NBER WORKING PAPER SERIES

\title{
PRICE DISCRIMINATION, COPYRIGHT LAW AND TECHNOLOGICAL INNOVATION: EVIDENCE FROM THE INTRODUCTION OF DVDS
}

\author{
Julie Holland Mortimer \\ Working Paper 11676 \\ http://www.nber.org/papers/w11676 \\ NATIONAL BUREAU OF ECONOMIC RESEARCH \\ 1050 Massachusetts Avenue \\ Cambridge, MA 02138 \\ September 2005
}

I thank John Asker, Steve Berry, Estelle Cantillon, Liran Einav, Gautam Gowrisankaran, Ali Hortacsu, Richard Mortimer, Ariel Pakes, Brian Viard, Paul Walsh and Mike Whinston for helpful discussions and comments. I also thank seminar participants at the Bureau of Economic Analysis, Columbia University, Duke University, Harvard University, Indiana University, Johns Hopkins University, MIT, Northwestern University, the National Bureau of Economic Research Summer Institute, the Stanford Institute for Theoretical Economics, University of Virginia, University of Wisconsin-Madison, Yale University, and the 2002 Workshop for Business and Economics Scholars at Florida Atlantic University for helpful comments. Chris Conlon provided excellent research assistance. The data for this study were generously provided to me by Rentrak Corporation, and I thank Ellen Dannenberg and Amir Yazdani for their help in collecting the data. Jerilyn Kessel at Centris provided additional data, and Brad Hackley provided helpful comments from the Video Software Dealers Association. I visited the Center for the Study of Industrial Organization during the course of this research, and am grateful for their hospitality and financial support. Any remaining errors are my own. The views expressed herein are those of the author(s) and do not necessarily reflect the views of the National Bureau of Economic Research.

(C2005 by Julie Holland Mortimer. All rights reserved. Short sections of text, not to exceed two paragraphs, may be quoted without explicit permission provided that full credit, including (C) notice, is given to the source. 
Price Discrimination, Copyright Law, and Technological Innovation: Evidence from the Introduction of DVDs

Julie Holland Mortimer

NBER Working Paper No. 11676

September 2005

JEL No. L0, O3

\section{$\underline{\text { ABSTRACT }}$}

This paper examines the welfare effects of intellectual property protection, accounting for firms' optimal responses to legal environments and technological innovation. I examine firms' use of indirect price discrimination in response to U.S. copyright law, which effectively prevents direct price discrimination. Using data covering VHS and DVD movie distribution, I explain studios' optimal pricing strategies under U.S. copyright law, and determine optimal pricing strategies under E.U. copyright law, which allows for direct price discrimination. I analyze these optimal pricing strategies for both the existing VHS technology and the new digital DVD technology. I find that studios' use of indirect price discrimination under US copyright law benefits consumers and harms retailers. Optimal pricing under E.U. copyright law also tends to benefit studios and consumers. I also reanalyze these issues assuming continued DVD adoption.

Julie Holland Mortimer

Harvard University Department of Economics

Cambridge, MA 02138

and NBER

mortimer@fas.harvard.edu 


\section{Introduction}

The welfare effects of intellectual property protection depend on how firms respond to the legal environment created by intellectual property laws (such as patent and copyright law), as well as technological innovations that affect the distribution of protected work. An important aspect of U.S. copyright law is a restriction that the law places on firms' abilities to directly price discriminate based on a consumer's intended use of a product. Firms may attempt to mitigate the effect of this restriction through legal indirect price discrimination. In addition to responding to legal restrictions, firms also face new challenges when copywritten content (e.g., music and movies) is digitalized. This technological change may alter firms' optimal pricing decisions. To identify factors influencing firms' optimal pricing decisions under current U.S. copyright law, I empirically examine the outcomes of two pricing strategies (no price discrimination and indirect price discrimination) used by firms for products that are identical in content but distributed via an old established technology and a new emerging technology. The analysis uses a new dataset covering the distribution of movies on VHS and DVD formats to explain why alternative pricing strategies may be optimal for the same movie distributed on different formats, and to establish the welfare effects of indirect price discrimination strategies in the context of the U.S. copyright law. I then estimate the welfare effects of optimal pricing strategies under an alternative form of copyright protection currently used in the E.U. that allows for direct price discrimination based on a consumer's intended use of a product. Finally, I consider the potential future effects of current and alternative copyright laws as adoption of the emerging technology continues and firms respond to changes in the composition of their consumers.

In 1979, Paramount began licensing Fotomat to sell videocassette tapes of its movies, and soon discovered that independent retailers were purchasing the tapes and renting them out at their own stores. This was (and is) legal under the U.S. Copyright Act of 1976, which stipulates that an owner of a legally-owned copy of a creative production has the right of "first use." This stipulation, commonly referred to as the First Sale Doctrine, invokes copyright jurisdiction only upon the first sale of videocassette tapes (or any other copyright-protected product), so that subsequent use, including resale and rentals, does not generate income to the copyright holder. ${ }^{1}$ The First Sale Doctrine is distinct from the

\footnotetext{
${ }^{1}$ In 1977, MCA/Universal and Disney jointly sued the Sony Corporation, which created and owned
} 
Fair Use Doctrine, which addresses duplication of copyrighted materials for the purpose of fair use (such as photocopying articles for distribution to a class or public showings of copywritten content). The First Sale Doctrine applies to all copyright-protected products and also allows for legal markets in used book, records/CDs, paintings, and other creative works. It is still an open question as to how First Sale Doctrine will be interpreted with respect to digital media, where transfering ownership of a legally-purchased copy, or allowing others to "rent" a legally-purchased copy generally requires duplication of the original. ${ }^{2}$

The First Sale Doctrine effectively strips movie studios of any ability to directly price discriminate between institutional (i.e., video rental stores) and individual users in the home video market, because any organization can purchase videos as an individual user and legally rent them out. Thus, movie studios in the U.S. do not charge different prices to video retail stores and individual buyers (although they can offer quantity discounts). In contrast, many other countries specify their copyright law so that copyright holders can restrict use of the product after first sale (e.g., the European Union and Australia, among others). When selling a movie to the home video market in these countries, studios do in fact charge very different prices to the two types of buyers.

In the face of the legal restrictions in the U.S., copyright holders in the motion picture industry adopted a form of intertemporal price discrimination. When releasing a movie for home video on the established VHS format, a firm initially sets a very high price for the videocassettes, during which time the buyers are typically video rental stores purchasing rental inventory. ${ }^{3}$ Subsequently, the firm lowers the price substantially, at which time

the rights to Betamax hardware, over alleged lost revenues from home recordings of broadcast television programs. In 1984, the Supreme Court voted five-to-four in favor of Sony in Universal v. Sony. The decision permitted home videotaping of copyrighted programs without royalty payments, but was more broadly interpreted to uphold the First Sale Doctrine, and the case paved the way for the emerging video rental retail industry (Childs, 1992).

${ }^{2}$ Recent examples of this in the news include an attempt to resell a digital music file on eBay (see http://blogcritics.org/archives/2003/09/10/131657.php and http://georgehotelling.net/90percent/geekery/ does the right of first sale still exist.php) and the effort by Google to copy the full content of three university libraries (Harvard, Stanford and the University of Michigan) into a searchable database (see the New York Times, August 13, 2005). As a result, digital media introduce issues of Fair Use as well as First Sale Doctrines.

${ }^{3} \mathrm{~A}$ similar pricing pattern is observed for textbooks. In many introductory courses, most students resell the textbook when the course ends, as allowed by the First Sale Doctrine. In response to this behavior, many new introductory level textbooks carry a high price as the publisher attempts to capture the resale value of the book. Thus, the discounted difference between the new and used prices is essentially the rental price of the book. Textbooks for more advanced courses, where students are less likely to resell the book, tend to carry a lower price. While intertemporal price discrimination is not used for any particular book title, the pricing strategies reflect similar market conditions created by the First Sale Doctrine. Chevalier and Goolsbee (2005) provide an analysis of publishers' choices to issue new editions of introductory textbooks. 
the typical buyers are end-users. ${ }^{4}$ This strategy is commonly referred to in the industry as "rental pricing," and has been used for approximately 90 percent of all titles on the VHS format historically. For the remaining titles, the initial rental window is forgone in favor of generating early (and potentially more) direct sales to consumers. For these titles, studios set a retail price in the range of $\$ 19.99$ - $\$ 26.99$ immediately upon the first release. ${ }^{5}$ This practice, referred to as "sell-through pricing," is typically used for children's titles, and occasionally for popular 'blockbuster' titles, especially movies with 'teenager' appeal. Examples of sell-through priced movies include Blair Witch Project, Titanic, and Antz. ${ }^{6}$

With the introduction of the DVD format, studios have almost exclusively adopted sellthrough pricing for a movie's DVD release, even as they maintain a rental-pricing strategy for the same-day release of the movie's VHS format. For example, The Green Mile was initially released with a VHS price of $\$ 107.95$ and a same-day DVD price of $\$ 24.95$. There are at least two possible explanations for this dramatic change in the pricing policy of the new format. On one hand, differences in the populations of consumers that adopt the DVD format in early years versus keeping the VHS format may lead to different optimal pricing choices. In this case, as more low-value consumers adopt DVD hardware and choose to rent rather than purchase on the DVD format, upstream firms (movie studios) might again choose to adopt a rental-pricing strategy in order to discriminate between the institutional and individual purchasers. ${ }^{7}$ On the other hand, the digital DVD format may be inherently different from the VHS format, allowing for convenient viewing of movies on laptop computers and portable DVD players. These new uses potentially affect the perceived quality

\footnotetext{
${ }^{4}$ Initial retail prices for VHS tapes under this strategy range from around $\$ 99.95$ to $\$ 107.95$. Approximately five months after its initial release, the studio re-prices the movie for "sell-through." At this time, the retail price falls to the range of $\$ 19.99$ - $\$ 26.99$ and videocassettes turn up for direct sale to consumers at mass merchandisers and video stores. Wholesale prices facing retailers are in the range of $\$ 60$ - $\$ 70$ in the first period, and then fall to $\$ 10$ - $\$ 15$ after the sell-through re-pricing. An inefficiency of intertemporal price discrimination is the occurrence of double-marginalization and understocking in rental markets, as retailers purchase only a small quantity of tapes at the high "rental" price. An important contractual change in the industry in the late 1990's and early 2000's has involved the use of revenue-sharing contracts to mitigate this source of inefficiency, and many studios are now participating in such programs. (See Dana and Spier (2001), and Cachon and Lariviere (2002), for theoretical analyses of such contracts, and Mortimer(2004) for an empirical analysis of the actual contracts.)

${ }^{5}$ Wholesale prices are in the range of $\$ 10-\$ 15$.

${ }^{6}$ Revenue-sharing contracts are typically not used on sell-through priced titles.

${ }^{7} \mathrm{~A}$ sell-through pricing strategy could be used in the initial phase of DVD hardware adoption in order to stimulate direct sales to "high-value" early DVD adopters, and to take advantage of any novelty effect that new hardware adoption has on purchases of software. Under this explanation, the use of sell-through pricing for the DVD format and rental pricing for the VHS format may help to price discriminate between institutional and individual buyers, as most "low-value" renters would still be using the VHS format.
} 
of owning and renting, and may lead to different optimal pricing choices. In this case, one would expect that sell-through pricing will remain the standard for pricing in the DVD market. $^{8}$

The first goal of this paper is to understand what factors influence a studio's choice of sell-through and rental pricing strategies, and why the choice of pricing strategy may differ for the same movie on the old VHS and new DVD formats. With that understanding, I seek to answer the following questions. First, what are the welfare implications of the different pricing strategies adopted under current U.S. copyright law? Second, what are the welfare implications of pricing strategies that would be optimal under the alternative form of copyright law widely used in other countries? Finally, assuming that all current VHS users eventually adopt DVD hardware in the future, how are the optimal pricing strategies and welfare estimates under each of the various copyright regimes affected?

I find that firms consistently choose the more profitable strategy across titles and formats, and that intertemporal price discrimination benefits consumers but harms retailers. Regarding the form of the copyright law, I find that price discrimination under an EUstyle law allowing for contemporaneous price discrimination tends to benefit studios and consumers at the expense of retailers for the new DVD format, but not necessarily for the VHS format. Finally, I find that EU-style copyright protection allows for a more profitable pricing strategy by copyright holders when consumers have fully adopted the new DVD technology, and that consumers benefit in this legal environment.

The paper proceeds as follows: section 2 discusses related literature and describes the home video industry. Section 3 lays out a demand system for rentals and purchases of a movie on a particular format and describes the upstream firm's choice of whether or not to use second- or third-degree price discrimination. In section 4, I describe the dataset and the timing of rentals and sales. Section 5 modifies the demand system to incorporate institutional details, describes the estimation strategy, and discusses results. Finally, section 6 describes the counterfactual experiments and provides the results of welfare analyses.

\footnotetext{
${ }^{8}$ An alternative explanation may be that piracy is easier on the digital DVD format, and a sell-through pricing strategy is aimed at discouraging piracy. The effects of piracy, however, are complicated: they depend on the upstream firm's ability to monitor piracy both by individuals and by video rental stores. While piracy may be easier with the digital format, monitoring capabilities-especially for video rental storeshave also improved dramatically in recent years.
} 


\section{Related Literature and the Home Video Industry}

\section{$2.1 \quad$ Related Literature}

A growing empirical literature addresses the topic of price discrimination, and a large literature addresses the theoretical implications of copyright provisions. However, to my knowledge, little empirical or theoretical literature addresses the welfare implications of copyright law through its influence on price discrimination strategies or other static best responses in product markets for copyrighted goods. Thus, this paper complements two distinct literatures. First, it studies the welfare implications of price discrimination, and compares the welfare effects of different forms of price discrimination (rental, sell-through, and EU-style pricing). Second, the paper examines the welfare effects of intellectual property protection, accounting for firms' strategic responses to the legal environment.

A related previous study on price discrimination is Leslie (2004), which examines the welfare effects of both second- and third-degree price discrimination in Broadway theater. ${ }^{9}$ Others have empirically studied the effects of price discrimination in the presence of competition. ${ }^{10}$ Also related to this study, Clerides (2002) examines the implementation of intertemporal price discrimination in book sales, and Bergstrom (2001) examines institutional pricing of academic journals. ${ }^{11}$

In the home video industry, a strategy of no price discrimination can be more profitable than a strategy of second-degree price discrimination, because there is a cost to implementing second-degree price discrimination (i.e., firms must reduce product quality by delaying the sell-through release to consumers). This is similar to treatments in the theoretical literature in which firms destroy quality in order to better sort consumers. ${ }^{12}$

\footnotetext{
${ }^{9}$ Previous empirical work on price discrimination primarily tested whether or not different instances of price dispersion had a cost-based explanation, or a price discrimination-based explanation (Borenstein (1991), Shepard (1991), Borenstein and Rose (1994), among others). Leslie (2004) makes the point that, in some cases, such as Broadway and home video, we know that price dispersion is not cost-based. Thus, the question of interest is quantifying the welfare effects of price discrimination.

${ }^{10}$ See McManus (2001), Miravete (2002), and Busse and Rysman (2004)).

${ }^{11}$ To the best of my knowledge, the difference in the pricing of VHS/DVD rentals and library subscriptions of academic journals (where direct price discrimination occurs) is founded in the public availability of the content of printed goods. Donations of personal subscriptions to libraries would be illegal due to "Fair Use" violations, because the content of library journals is, in principle, available to the public, whereas the content of a DVD is not. Similarly, copyright holders could charge a higher price for the sale of music or movies intended to be played or shown publicly, as this act would fall under the public performance rights of the copyright holder, and thus subject to Fair Use.

${ }^{12}$ Mussa and Rosen (1978) is a seminal contribution; Maskin and Riley (1984) extend their model, and Deneckere and McAfee (1996) also model damaged goods.
} 
The welfare effects of intellectual property protection have been studied in other contexts, often focusing on the optimal theoretical level of copyright protection for the purpose of inducing investment in creative works ${ }^{13}$, or the theoretical effects of piracy or unauthorized copying on firm profits and social welfare ${ }^{14}$. Perhaps the most closely related previous paper is Liebowitz (1986), which studies the impact of price discrimination by journal publishers on the working of copyright law. The treatment is primarily theoretical, although it reports some basic data on the prevalence of price discrimination in the market for academic journals and is based on work involving a Betamax court case. A much larger literature on intellectual property protection has focused on patent, rather than copyright, protection. An exception is McCalman (2004), which studies the governance structures and licensing behavior of movie studios across countries with different levels of intellectual property rights protection. ${ }^{15}$ The role of purchase and rental markets to segment high- and low-value consumers has also been studied theoretically by Varian (2000), and an historical background of the video rental industry is provided in Varian and Roehl (2001). Varian (2000) derives conditions under which pricing exclusively for a rental market, or pricing exclusively for direct sale, will be more profitable for the owner of an information good. ${ }^{16}$

\subsection{Industry Background}

In 1999, the $\$ 16$ billion home video industry accounted for $55 \%$ of studios' domestic revenues, compared to $22 \%$ generated by theatrical revenues, and $23 \%$ from all other forms of media, such as the sales of pay-per-view, cable, and broadcast television rights. ${ }^{17}$ Approximately 20,000 home video retailer outlets plus internet firms such as Netflix purchase movies on VHS or DVD format and rent their inventory to consumers. In addition, consumers may purchase movies on either format from video, non-specialized, or Internet retailers. Table 1

\footnotetext{
${ }^{13}$ See Novos and Waldman (1984) and Yoon (2002).

${ }^{14}$ see Ordover and Willig (1978), Johnson (1985), Liebowitz (1985), and Takayama (1994 and 1997).

${ }^{15}$ Also related, McCalman (2001) studies the welfare effects of harmonizing patent protection across countries (via the TRIPs agreement of the Uraguay Round of GATT negotiations) by estimating a structural model of innovation using a modified version of the model in Eaton and Kortum (1996).

${ }^{16}$ Varian identifies three factors that play a role in determining the more profitable strategy: transactions costs of renting compared to the marginal cost of production, the number of times content is viewed, and the ability to use a rental market to segment high- and low-value consumers. The model I derive is very similar in spirit-the main difference is that my model also incorporates intertemporal segmentation. Thus, in the absence of contemporaneous market segmentation that might be achievable under a less restrictive copyright law, the choice becomes whether to price discriminate intertemporally or not.

${ }^{17}$ VSDA Annual Report, 1999.
} 
outlines market shares of rentals and purchases according to the type of retail outlet where the rental or purchase occurred, including video specialty stores, discount merchandisers such as Walmart, Internet (both sales and Netflix rentals), and others. ${ }^{18}$

The data for the present study are drawn from the population in the first row of table 1, 'Video Specialty retailers,' although I make use of the data in the other rows of table 1 to weight my estimated market shares. As shown in table 1, Video Specialty retailers represent nearly 77 and 74 percent of all VHS and DVD rentals respectively. However, a greater proportion of sales occur through alternative distribution channels, including Internet and non-specialized retail outlets, and so it is important to weight the sample accordingly.

As discussed in the introduction, the distribution of videocassettes on the VHS format often exhibits a form of intertemporal price discrimination, while the distribution of the same movie on the DVD format displays no price discrimination. To understand the welfare implications of alternative forms of copyright protection, it is necessary to first describe the different optimal pricing strategies under current copyright law. Under "rental pricing," video retailers pay a linear wholesale price to the distribution arm of a movie studio (or "distributor") for each pre-recorded videocassette tape of a movie of around $\$ 60$ to $\$ 70 .{ }^{19}$ After an initial period of rental activity (around five months), the distributor cuts the wholesale price from the $\$ 60$ - $\$ 70$ range to $\$ 10$ - $\$ 15$, called "sell-through re-pricing." At this time the movie is commonly sold to individual users. This two-tiered pricing strategy is a form of intertemporal price discrimination and helps to distinguish between institutional (i.e., video stores) and individual buyers. Exceptions to this typical two-tiered pricing pattern are titles priced for "sell-through." In this case, intertemporal price discrimination is discarded in favor of an immediate low price to stimulate early sales to individual users. ${ }^{20}$

Tables 2 and 3 detail the use of sell-through pricing for the VHS and DVD formats respectively. These figures are compiled from the dataset described in the next section, and include all major titles released between January 2000 and December 2001. Titles classified

\footnotetext{
${ }^{18}$ The table is constructed from weekly data gathered through phone surveys of consumers' purchase and rental habits provided by Alexander and Associates and reflect market shares as of the spring of 2002.

${ }^{19}$ According to industry sources, the marginal cost of producing, packaging and shipping a pre-recorded videocassette tape is around two dollars, and that of a DVD is around $\$ 1.25$.

${ }^{20}$ Wholesale price discounts off of suggested retail prices were obtained through interviews with studio executives. In addition to these traditional pricing strategies, revenue-sharing contracts became a widelyused contractual arrangement between retailers and distributors beginning in 1998. These distribution contracts are discussed in detail in Mortimer (2004). For the present analysis, I focus on 41 titles with theatrical box office revenues of more than 55 million dollars, and for which revenue-sharing contracts were not available. More detail is provided in the next section which describes the data.
} 
as "B" or "A" earned 15-40 million or more than 40 million respectively in theatrical boxoffice revenue. Table 2 shows the incidence of sell-through pricing for titles released on VHS. Childrens and Family movies are always sell-through priced, while Romance titles are never sell-through priced in the dataset. Science Fiction titles are somewhat more likely to be sell-through priced than rental priced if the title has a large theatrical box-office, but are quite unlikely (17 percent) to be sell-through priced if the theatrical performance was poor. Contrasting to this, table 3 shows the use of sell-through pricing for the same movies under the DVD format. With the exception of a single B title in the Drama genre, all titles are sell-through priced.

Finally, growth rates of DVD rentals and sales and DVD hardware adoption are presented in Table 4 for the period of analysis. DVD households, which count households with one or more DVD players and excludes households in which the DVD player is attached to a PC but not used for entertainment, grew from 12 million at the end of 2000 to 24 million at the end of 2001. Quarterly growth rates show faster growth during the fourth quarter of each year due to holiday purchases. The rate of DVD hardware adoption has been extraordinarily fast: as much as 10 times faster than VCR adoption according to some industry sources. Anecdotal evidence suggests that in addition to purchasing the new hardware to augment or replace an existing VCR, consumers have also replaced CD players with DVD machines. DVD rentals and sales have also shown fast growth. The second and third rows of table 4 show total expenditures on DVD rentals and sales, and rows 4 and 5 show the implied growth rates. Rentals grew at a pace of 90 percent from 1999 to 2000, and grew even faster, at a rate of 146 percent, in 2001. Sales grew 146 percent from 1999 to 2000, and grew at a rate of 66 percent in 2001. Interestingly, the pattern of growth rates of rentals and sales is consistent with an adoption pattern in which consumers with relatively low willingness to pay for movie quality (i.e., consumers more likely to rent than buy) adopt DVD hardware later than consumers with high willingness to pay for movie quality (i.e., consumers more likely to buy than rent). Of course, this is merely suggestive evidence, and in no way establishes a relationship between observed growth rates and unobservable willingness to pay for movie quality. 


\section{Overview of Demand and Supply}

In this section, I outline a model of consumer demand and firm behavior restricted by current copyright law that specifies the conditions under which second-degree price discrimination (i.e., rental pricing) is a more profitable pricing strategy than non-discriminatory linear pricing (i.e., sell-through pricing). I also compare these outcomes to the results under an alternative copyright law where firms are able to use third-degree price discrimination by concurrently charging different prices to different types of users. The model consists of a demand system for consumers and a supply decision for the firm. ${ }^{21}$ Consumers consider a single product that is vertically-differentiated according to whether or not the product is rented or purchased..$^{22}$ The supply decision specifies firms' profit functions and solves for the optimal pricing strategy. I consider three possibilities. First, the firm is able to simultaneously charge different prices in the two markets (rental and purchase). This is a common pricing strategy in the E.U., but is not feasible in the U.S. market because of the First Sale Doctrine. Second, I consider simple linear pricing without price discrimination. Finally, I consider the use of intertemporal price discrimination where the value of purchasing the product declines over time. This general overview is intended to provide a framework for describing the data and the estimation procedures in the following sections.

\subsection{Consumer Demand}

To motivate the supply decision, consider a standard model of consumer demand for two vertically-differentiated products: the rental or purchase of a given movie title on a particular format. ${ }^{23}$ For each title, I assume that the upstream firm (in this case, the movie studio) has monopoly ownership of that title. ${ }^{24}$ Consumers' utility functions are specified by:

\footnotetext{
${ }^{21}$ I focus here on the supply decision of the firm that holds the copyright on the good, or the upstream firm. I do not explicitly model the strategic behavior of downstream firms in response to upstream pricing changes in this section. However, in the empirical work, I incorporate all downstream markups, which are measured in the data. I also provide further discussion of this issue in the section on counterfactual policy experiments.

${ }^{22}$ In the empirical work, I also distinguish between purchases of used and new tapes. Further discussions of this issue appear in the data description and estimation sections.

${ }^{23}$ Bresnahan (1987) used a vertically-differentiated model to analyze the automobile industry; Song (2004) is a more recent example in which a vertically-differentiated model is estimated. Much of the notation used here follows that in Berry (1994).

${ }^{24}$ In section 5 I discuss this assumption in detail.
} 


$$
\begin{array}{cl}
\delta_{s}-\alpha_{i} p_{s} & \text { if purchase } \\
u_{i}=\delta_{r}-\alpha_{i} p_{r} & \text { if rent } \\
0 & \text { otherwise }
\end{array}
$$

The parameters $\delta_{s}$ and $\delta_{r}$ represent the quality of purchasing and renting respectively; $p_{s}$ and $p_{r}$ denote the prices for purchasing and renting the good. The parameter $\alpha_{i}$ represents a consumer's marginal utility of income and differs across individuals according to their income level and their unobservable willingness to pay for movie quality. ${ }^{25}$

Consumers prefer to purchase when $\delta_{s}-\alpha_{i} p_{s}>\delta_{r}-\alpha_{i} p_{r}$, and they prefer to rent when $\delta_{s}-\alpha_{i} p_{s}<\delta_{r}-\alpha_{i} p_{r}$ and $\delta_{r}-\alpha_{i} p_{r}>0$. Assuming that the quality of purchasing is greater than the quality of renting $\left(\delta_{s}>\delta_{r}\right)$, and also assuming an interior equilibrium (such that each product has non-zero market share), consumers purchase if their value of $\alpha_{i}$ is sufficiently low:

$$
\alpha_{i}<\frac{\delta_{r}-\delta_{s}}{p_{r}-p_{s}} \equiv \tilde{\alpha}
$$

And consumers rent if their value of $\alpha_{i}$ meets the conditions:

$$
\alpha_{i}>\frac{\delta_{r}-\delta_{s}}{p_{r}-p_{s}} \text { and } \alpha_{i}<\frac{\delta_{r}}{p_{r}} \equiv \hat{\alpha}
$$

Consumers with $\alpha_{i}>\hat{\alpha}$ consume the outside good. Thus, if $N$ is the number of consumers in the market, demand is given by

$$
\begin{array}{cl}
N(F(\tilde{\alpha})) & \text { in purchase market } \\
N(F(\hat{\alpha})-F(\tilde{\alpha})) & \text { in rental market. }
\end{array}
$$

where $F(\alpha)$ is the cumulative distribution function of $\alpha$.

\subsection{Supply}

The rental and sales markets for VHS and DVD formats of a movie are both characterized by a vertically-separated industry structure, in which retailers and studios are separately owned. ${ }^{26}$ Consider an example with a single retailer and a single studio; I specify profit functions for the retailer and studio in the sales market for one movie on one format as:

\footnotetext{
${ }^{25} \mathrm{As}$ is well-documented, we can also re-write this so that the $\alpha_{i}$ parameter modifies the $\delta$ parameter and thus affects the 'taste' for purchasing or renting the movie. See Tirole (1995) pp. 96-97.

${ }^{26}$ In later sections of the paper, I distinguish between the VHS and DVD markets, and allow the parameters of the model to vary across formats.
} 


$$
\begin{gathered}
\pi_{r e t}^{s}=N(F(\tilde{\alpha})) \cdot\left(p_{s}-p_{w}^{s}\right), \text { and } \\
\pi_{s t u d}^{s}=N(F(\tilde{\alpha})) \cdot\left(p_{w}^{s}-c\right)
\end{gathered}
$$

The parameter $c$ is the production cost for the studio, and $p_{w}^{s}$ represents the wholesale price charged to retailers by the upstream studio. If there is perfect competition in the retail sector and no additional costs incurred by the retailer, $p_{s}=p_{w}^{s}$. The presence of any mark-ups or additional costs for the retailer at the point of sale would lead to $p_{s}=p_{w}^{s}+\mu_{s}$ where $\mu_{s}$ is the retail mark-up.

In the rental market, retailer and studio profits are given by:

$$
\begin{aligned}
& \pi_{r e t}^{r}=N(F(\hat{\alpha})-F(\tilde{\alpha})) \cdot\left(p_{r}-p_{w}^{r} / \tau\right), \text { and } \\
& \pi_{\text {stud }}^{r}=N(F(\hat{\alpha})-F(\tilde{\alpha})) \cdot\left(p_{w}^{r}-c\right) \cdot(1 / \tau) .
\end{aligned}
$$

In these specifications, $\tau$ is the number of rentals produced by each copy of the movie/format sold to the rental market. ${ }^{27}$ If there is perfect competition in the retail sector and no additional costs incurred by the retailer, $p_{r}=p_{w}^{r} / \tau$. Again, the presence of mark-ups or additional costs incurred by the retailer at the point of sale would lead to $p_{r}=p_{w}^{r} / \tau+\mu_{r}$. Assuming retailer mark-ups are zero for the purpose of this example, the upstream firm maximizes:

$$
\max _{\left\{p_{w}^{r}, p_{w}^{s}\right\}} \pi_{s t u d}=N(F(\tilde{\alpha})) \cdot\left(p_{w}^{s}-c\right)+N(F(\hat{\alpha})-F(\tilde{\alpha})) \cdot\left(p_{w}^{r} / \tau-c / \tau\right)
$$

where $\tilde{\alpha}=\tilde{\alpha}\left(p_{s}, p_{r}, \delta_{s}, \delta_{r}\right)$ and $\hat{\alpha}=\hat{\alpha}\left(p_{r}, \delta_{r}\right)$ as before. ${ }^{28}$

\section{Market Segmentation (Third-degree Price Discrimination)}

Under third-degree price discrimination, the upstream firm sets different prices in the 2 markets simultaneously. Note that when retailer mark-ups are zero,

$$
\hat{\alpha}=\frac{\delta_{r}}{p_{w}^{r} / \tau}, \text { and } \tilde{\alpha}=\frac{\delta_{r}-\delta_{s}}{p_{w}^{r} / \tau-p_{w}^{s}} .
$$

All rental stores pay $p_{w}^{r}$ due to the assumption of zero retailer mark-ups (which is relaxed in the empirical work), all consumers pay $p_{w}^{s}$; and rental consumers pay $p_{w}^{r} / \tau$ for a rental. This

\footnotetext{
${ }^{27}$ Of course, one can always consider more complicated relationships between the inventory decisions of the retailer and the production of rentals. Mortimer (2004) addresses this issue and compares robustness tests of alternative views of the $\tau$ variable in the context of revenue-sharing programs. I provide further discussion in the section on counterfactual policy experiments.

${ }^{28}$ The appropriate retailer mark-ups are observed in the data and incorporated in estimation.
} 
strategy is not feasible under current U.S. Copyright law because firms are not allowed to charge different prices for different uses of the product, but it represents a strategy available to (and used by) firms in many other countries, including all the countries in the E.U..

\section{No Price Discrimination}

The second case considers the upstream firm's pricing problem in the absence of price discrimination (sell-through pricing). I denote the single wholesale price as $p_{w}$. Note that the cutoffs which affect market shares (again assuming retailer mark-ups are zero) are now:

$$
\hat{\alpha}=\frac{\delta_{r}}{p_{w} / \tau}, \text { and } \tilde{\alpha}=\frac{\delta_{r}-\delta_{s}}{p_{w}-p_{w} / \tau}
$$

The difference between the first case and the second case is that in the first case (equation 3 ), the relative price of a sale compared to a rental is under the control of the upstream firm (i.e., $\tilde{\alpha}$ depends on $p_{w}^{s}$ and $p_{w}^{r}$ ). In the second case (equation 4), relative prices for a purchase versus a rental are constrained by $\tau$ (i.e., $\tilde{\alpha}$ depends only on $p_{w}$, because $p_{w}^{s} / p_{w}^{r}$ must equal $\tau$ ). Thus, copyright holders can only set one price, and the price of the second use of the good is then determined by the technology in the downstream market.

While the no price discrimination strategy is consistent with the U.S. copyright law and used for virtually all movies released on the DVD format, the restriction of only being able to set a single price can be very costly to studios. In the absence of the ability to use thirddegree price discrimination to segment the market under U.S. copyright law, upstream firms recognized that it might be possible to discriminate over time, thus adopting a rental-pricing strategy for many movies, in which price is lowered about five months after a title's initial video release. Theoretically, there is no reason to rule out a much more flexible use of the temporal dimension, where firms adjust their prices at many points in time. ${ }^{29}$ In practice, however, upstream firms in this industry have consistently chosen a single repricing date, effectively using two time periods over which to discriminate. Consequently, I focus on firms' decisions to either price discriminate over two periods or to not price discriminate at all, and the effects of these decisions on consumers.

\section{Intertemporal Discrimination Over Two Time Periods}

(Second-degree Price Discrimination)

The third case considers intertemporal price discrimination over two time periods (rental

\footnotetext{
${ }^{29}$ Indeed, there is also no reason to rule out the use of intertemporal price discrimination under EU-style copyright law (in addition to segmentation by use), and one might be interested in the potential welfare effects of such a pricing strategy.
} 
pricing). Suppose that the value of the good to consumers decays, so that the value of purchasing in the later period is $\delta_{s 2}<\delta_{s} .{ }^{30}$ This is meant to reflect such effects as wordof-mouth, movie reviews, theatrical advertising, and other factors that might influence the quality of purchasing a movie over time, relative to the standard discount factor. ${ }^{31}$

I make the assumption, consistent with industry facts, that the rental market is fully served in period one. ${ }^{32}$ In other words, I assume that there are not "second-run" video stores that delay purchasing new releases until after the new release has been re-priced. Such video stores do not seem to be a prevalent feature of the rental market, and so I make no distinction between a rental in period two and consumption of the outside good. The use of intertemporal price discrimination introduces a third product into consumers' choice sets. Consumers can rent in period 1, wait and purchase in period 2, or they can purchase in period 1, (i.e., at the same time as video rental stores). Thus, consumers maximize utility over the choices:

$$
u_{i}=\begin{array}{cl}
\delta_{s}-\alpha_{i} p_{w}^{r} & \text { if purchase in period } 1 \\
\delta_{s 2}-\alpha_{i} p_{w}^{s} & \text { if purchase in period } 2 \\
\delta_{r}-\alpha_{i} p_{w}^{r} / \tau & \text { if rent in period } 1 \\
0 & \text { otherwise }
\end{array}
$$

where $p_{w}^{r}$ is the price of purchasing in period 1 , and $p_{w}^{s}$ is the price of purchasing in period 2. The price of a rental is $p_{w}^{r} / \tau$, and the cutoff points across the distribution of $\alpha$ are now:

$$
\hat{\alpha}=\frac{\delta_{r}}{p_{w}^{r} / \tau}, \tilde{\alpha}=\frac{\delta_{r}-\delta_{s 2}}{p_{w}^{r} / \tau-p_{w}^{s}}, \text { and } \bar{\alpha}=\frac{\delta_{s 2}-\delta_{s}}{p_{w}^{s}-p_{w}^{r}}
$$

While the firm has more control over the relative prices of rentals and sales compared to no price discrimination, ( $\tilde{\alpha}$ and $\bar{\alpha}$ depend on $p_{w}^{r}$ and $p_{w}^{s}$ rather than a single $p_{w}$ ), the value of the product for purchase in period 2 is lower than in period 1 . The use of market

\footnotetext{
${ }^{30}$ The quality decay differs from the usual discount factor because it does not apply equally to the quality of the movie and the price and cost factors. One could easily incorporate a discount factor for price and cost: the simplifying assumption here is that the standard discount factor is equal to one.

${ }^{31} \mathrm{~A}$ more critical simplifying assumption in the model is that upstream firms do not choose the extent of decay (for example, by engaging in special sales-oriented advertising campaigns or other initiatives). However, it is difficult to identify such effects empirically, and I have no reason to believe that the 'choice' of quality decay is a first-order decision for the upstream firm in this context.

${ }^{32}$ One could extend the model to explicitly incorporate the cost structures and profit maximization problem facing retailers. The assumption that the rental market is served in the first period holds as long as there is sufficient competition between the video rental retailers, or between video retailers and other distribution channels for a movie such as cable, pay-per-view, etc. The assumption that the rental market is served in period one is supported empirically.
} 
segmentation within each period would be strictly preferred, because the firm could then set a first-period price for purchase in addition to the second-period purchase price and the first-period rental price. The third-degree price discrimination case discussed earlier is a corner solution of the two-period market segmentation strategy in which the firm sets prices to induce all consumers to purchase in period one. I leave a proof of the conditions under which the corner solution with market segmentation is optimal for later, and proceed with a comparison of the three (non-nested) cases. ${ }^{33}$

Under current U.S. copyright law, the model indicates that the decision of a firm to use second-degree price discrimination, or no price discrimination, depends upon 1) the decay rate of the quality of owning between the first and second periods, 2) the distribution of $\alpha$, and 3) the relative qualities of renting and owning. ${ }^{34}$ In simulated results reported in appendix A, I show that intertemporal price discrimination becomes relatively more attractive as: the decay rate falls, the quality of owning in the second period falls relative to the quality of owning in the first period, or the expected value of $\alpha$ rises. These results are intuitive: for example, the cost to the firm of delaying sales to the second period falls as the decay rate falls, lowering the cost of intertemporal price discrimination and making it more attractive. Also, if the relative value of renting is high compared to owning, there is a stronger incentive to price discriminate between institutional and individual buyers because institutional buyers face higher demand and are thus willing to pay more for their rental inventories. Finally, as the average consumer price sensitivity increases ( $\alpha$ rises) there is greater incentive to price for the rental market, because the size of the potential 'sell-through' market is smaller.

\section{Data}

\subsection{Primary Data Sources}

The primary dataset used for this study is a new dataset provided by Rentrak Corporation. Independent retailers, as well as many large retail chains, rely on Rentrak as a central source for the provision of monitoring services in the home video industry. Monitoring through the Rentrak system occurs for all titles in each retail location. Over 10,000 retailers used

\footnotetext{
${ }^{33}$ Note that, in the absence of market segmentation, sell-through pricing is preferred to rental-pricing whenever the optimal second-period price exceeds the optimal first-period price, because consumers cannot be prevented from purchasing in the first period, and will indeed choose to do so.

${ }^{34}$ Conditional on the rental technology $(\tau)$.
} 
Rentrak between 1998 and 2001, accounting for over half of all retailers in the industry. ${ }^{35}$

Mortimer (2004) uses an earlier dataset collected from Rentrak, which covers VHS transactions during the years 1998 - 1999. In the new dataset used here, I observe both DVD and VHS transactions at 4,341 stores from January, 2000 through June, 2002. I eliminate 2,128 stores that did not carry most major titles during the period. This eliminates stores that either exited the database at an early date, or entered the database at a late date. This leaves a dataset with 2,213 stores whose rental and sales transactions are recorded for each title in each week from January 2000 to June 2002, and who have complete demographic and phone book data.

I observe store location at the county, zip code, and Designated Market Area (DMA) level for each of the 2,213 stores. $^{36}$ For each title, I observe theatrical box-office revenues, genre (such as Action/Adventure, Children's, etc.), and MPAA rating (such as R, PG-13, etc.). I focus on titles with theatrical box office revenues of at least 55 million in order to ensure sufficient coverage of the sales market. I discard titles released after December, 2001 so that rental and sales activity for each title is tracked for at least 6 months on both formats. Finally, I limit my attention to titles that are not available on revenue-sharing contracts. ${ }^{37}$ This leaves 41 major titles in the analysis. An observation is a store-title pair, which is constructed after summarizing over weekly transactions data; summary statistics appear in the next section.

The Rentrak dataset is an especially rich source of information on firm behavior. However, Rentrak cannot provide information on local competitive conditions facing each store in the database. In order to observe (or at least proxy) for local competitive conditions, I use Yellow Pages listings for all video retail stores in the United States, including Blockbuster and Hollywood Video stores, for 2000 through 2002. From these data, I identify the total number of video retail stores within the same zip code of each observed store in the Rentrak database. In addition, I utilize data from the 2000 US Census on the demographic

\footnotetext{
${ }^{35}$ Blockbuster Video and Hollywood Video comprise about 4,000 of these retailers, and I do not observe their transactions. Blockbuster Video does not release their data, and only process some titles through Rentrak's system. Hollywood Video recently settled a lawsuit with Rentrak involving a dispute over data integrity.

${ }^{36}$ Designated Market Areas organize the United States according to the coverage areas of broadcast television.

${ }^{37}$ Approximately half of the major studios offer revenue-sharing contracts at this time. Although I do not observe title or studio names, I do observe that many of the remaining titles come from two studios that are fairly large in terms of releases. The title and studio characteristics look quite representative of other titles in the database.
} 
characteristics of each zip code. Demographic data include the number of people, median income, and marginal distributions of race, education, age, gender, employment, family status, and the level of urbanization in each zip code. These three data sources (phone book listings, demographics, and transactions data) are merged by zip code. When estimating the model, I define a local market as a zip code area and use the merged data to characterize local market conditions. Clearly, zip code areas are designed to provide convenient local areas for the purposes of delivering mail, rather than as definitions of local markets. However, zip code areas appear to be a reasonable demarcation between markets in this setting: the average zip code area contains approximately 24,000 people and 2.6 video retail stores. Larger areas, such as 4-digit zip code areas or Metropolitan Statistical Areas (MSA's) are also feasible ways of attaching local demographic and business listing information, but seem to cover too large a geographic area for most video store customers.

\subsection{Auxiliary Data Sources}

An additional step for defining markets is to specify the portion of consumers that are active in the market for either the DVD or VHS format. For this, I use data from Centris on monthly DVD hardware penetration rates. ${ }^{38}$ Centris surveys consumers each month on whether or not they own a DVD console, and weights each consumer survey response according to a demographic weighting scheme. For more detail on the Centris data, see Karaca-Mandic (2003). The Centris data begin their coverage in the late 1990's and continue through June 2001. I aggregate the individual surveys in each state to calculate an implied state-level DVD hardware penetration rate. Due to the limitations of the survey size in each month, and the noisiness of the weighting scheme, I then fit a linear trend in each state across the eighteen months of January 2000 through June 2001. I use these fitted penetration rates in each month in each state as the actual penetration rates, and I assume that they are uniform within a state during that month. ${ }^{39}$ I assume that after a household has purchased a DVD player, they always rent or purchase on the new DVD format, although they may record and watch previously-purchased VHS movies on the old VCR.

The number of consumers in a market, denoted as $N$, takes on a value appropriate for either the VHS or DVD market by state and month. I denote $N_{m, q}^{V H S}$ and $N_{m, q}^{D V D}$ as the

\footnotetext{
${ }^{38}$ I thank Pinar Karaca-Mandic for her help in acquiring these data.

${ }^{39}$ One would of course like to have even more detailed information on these penetration rates, but these are the best data available to my knowledge.
} 
number of consumers in market $m$ and month $q$ that rent and purchase movies on VHS and DVD formats respectively. The estimates of $N_{m, q}^{V H S}$ and $N_{m, q}^{D V D}$ in each market are:

$$
\begin{aligned}
& N_{m, q}^{V H S}=\left[H H \cdot\left(0.90-D V D_{q}\right)\right] / S T O R E S_{m, y} \\
& N_{m, q}^{D V D}=\left[H H \cdot D V D_{q}\right] / S T O R E S_{m, y}
\end{aligned}
$$

where 0.90 is the national penetration of VCRs, assumed to be constant across markets, the variable $\mathrm{HH}$ is the number of households in the zipcode from the 2000 U.S. Census, and the variable $D V D_{q}$ is the penetration rate of DVD hardware in the relevant state and month. ${ }^{40}$ The variable $S T O R E S_{m, y}$ is the number of video specialty stores listed in the phonebook for that zipcode in a particular year. Typically, I observe roughly 1 of 3 stores in each zipcode neighborhood. Unfortunately, I do not observe rentals and sales at other stores. Dividing $N$ by the number of stores in the market inflates my observed sales and rentals at a single store to be representative of the local zip-code area, under the assumption that the unobserved stores have the same characteristics and sales as the observed store, and that phonebook listings represent the total population of video specialty stores.

The market for sales of VHS tapes and DVDs also includes some sales of used tapes from stores' rental inventories. Unfortunately, the primary data source does not record sales transactions separately as used or new. Thus, the best definition I have for distinguishing between new and used products is on the basis of price. I estimate wholesale price as being equal to 60 percent of the suggested retail price. This estimate is also borne out by industry interviews. Thus, I classify a sale as 'used' if the average weekly price of sales for a given title at a particular store is below the wholesale price of a new tape. This classification identifies approximately $80-85$ percent of all sales at my observed video specialty stores as used. I checked these estimates with professionals in the industry and with more detailed tabulations of the phone-survey data in Table 1. For purposes of weighting the sales and rental observations, I assume that all sales of used tapes occur through video specialty stores (and not, for example, through mass-merchandisers like Walmart).

A final distinction about market size relates to the fact that I only observe rental and sales transactions from video specialty stores, and not from discount merchandisers or Internet firms. Thus, I need to weight the observed rentals and sales according to the market share of the stores in my database. For this, I use the phone-survey data described in table

\footnotetext{
${ }^{40} \mathrm{I}$ match up titles to the monthly state penetration figures based on the month in which a title was released. The figure for overall VCR penetration (0.90) is from the VSDA 2002 Annual Report.
} 
1. I assume that purchases from discount merchandisers and Internet firms, etc., occur with equal probability across zipcode areas, and that used tapes are only sold by video specialty stores. The phone-survey data include both used and new sales. Thus, the weight in table 1 gives the weight to be applied for all sales (used plus new). In order to get the correct weight for new sales, I calculate the total number of weighted sales, subtract used sales, and calculate the appropriate weight for new sales. I do this for each store-title pair on each format, using format-specific weights from table 1. Now I can write down the relevant market size for each store-format-product as:

$$
\begin{aligned}
& N_{r, m, q}^{V H S}=0.768 \cdot N_{m, q}^{V H S} \\
& N_{u, m, q}^{V H S}=N_{m, q}^{V H S} \\
& N_{s, m, q}^{V H S}=W_{V H S} \cdot N_{m, q}^{V H S} \\
& N_{r, m, q}^{D V D}=0.738 \cdot N_{m, q}^{D V D} \\
& N_{u, m, q}^{D V D}=N_{m, q}^{D V D} \\
& N_{s, m, q}^{D V D}=W_{D V D} \cdot N_{m, q}^{D V D}
\end{aligned}
$$

where $W_{V H S}$ and $W_{D V D}$ are vectors of new sales weights for each store-title pair on VHS and DVD formats respectively. This definition of market size effectively weights the sample of stores appropriately to reflect the national market for the upstream firm. ${ }^{41}$ It would be wonderful to have data on new sales from other outlets, such as mass-merchandisers. Unfortunately, I do not observe title identity, so collecting and matching such data is not possible.

Finally, there is substantial variation across stores in the price paid for a rental or sale by a consumer. Most stores rent and sell used tapes for the 41 titles in the analysis, and charge different prices. However, some stores have zero market share for new sales of a title. $^{42}$ When I observe a zero market share for new sales, I assume the local price is equal to the suggested retail price, with the exception that rental-priced VHS titles are assigned the wholesale price faced by a retailer before re-pricing, and they are assigned the re-priced SRP after re-pricing.

\footnotetext{
${ }^{41}$ I have also estimated the model assuming that sell-through priced VHS titles have the same representation across video stores and mass merchandisers as DVDs. This does not change the results in any meaningful way.

${ }^{42} \mathrm{An}$ additional motivation for selecting titles with at least 55 million in theatrical box-office receipts is that there is broad coverage of the titles across many stores. This is especially important for shares of new sales, which are under-represented in my dataset.
} 


\subsection{Timing of Rentals and Sales}

Table 5 provides summary statistics from the data on both the quantity and timing of rentals and sales on both formats. For the 41 titles used in the analysis, I compute weekly totals of rentals and sales for each title based on the first week it appeared at a store. The top half of the table refers to those titles with a rental priced VHS release. The bottom half of the table refers to those titles with a sell-through priced VHS release. All titles (including those with a rental priced VHS format) are sell-through priced on the DVD format. Of the 41 titles, 29 are sell-through priced (in the lower half) while 12 are rental priced (in the top half). The left half of the table reports total rentals and sales, and cumulative monthly rental and sales activity for the VHS format, while DVD results are reported in the right half of the table.

I first discuss the timing of rentals and sales, and then discuss the totals and weighted totals for the four different classifications of titles: rental priced VHS titles in VHS and DVD formats, and sell-through priced VHS titles in VHS and DVD formats. Columns 1 and 4 provide information on the timing of rentals over months for VHS and DVD. Across all four categories, approximately two-thirds of all rentals occur during the first eight weeks (2 months). At least 85 percent of all rentals occur in the first 21 weeks (5 months).

Columns 2 and 5 examine used sales. Relatively few sales of used VHS tapes or DVDs occur during the first two months when the rental market is most active; however, by week 21, roughly half of all used sales have occurred. I do not distinguish between the timing of used sales for three reasons. First, unlike rentals and new sales, the sales of used tapes are not as clearly delineated by timing. Second, the choice of whether or not to use intertemporal price discrimination, and the effects of price discrimination on producer and consumer surplus are not likely to be affected by the distinction between early and late used sales. Finally, in table 6, there is little difference in the price of used tapes over time; in fact, the average price of a used tape is actually higher in later months than in early months for DVDs that were rental priced on VHS. The timing of rentals and used sales are similar across the four quadrants of table 5 .

Finally, columns 3 and 6 examine the timing of the sales of new tapes or DVDs. For rental priced VHS titles, relatively few sales of new tapes (less than 15 percent) occur during the first five months. In contrast, roughly three-fourths of all new sales take place in the first five months for sell-through priced VHS titles, and this figure is nearly 85 percent for 
all DVD titles. I classify sales occurring during the first 5 months as "period 1 sales." It is straightforward to test the robustness of my estimates to perturbations in this cut-off point. There were two reasons that I chose 5 months as the cut-off point between the two periods of the model. First, this corresponds to the timing of the sell-through re-pricing done by the studio for rental priced VHS titles. Second, the data seem to conform best to this definition when one examines table 5 .

Strictly speaking, the theory model described earlier predicts that 100 percent of new sales should occur during period 1 for DVDs and for sell-through priced VHS. The fact that 15 to 25 percent of the sales actually occur in my period 2 could reflect either consumers who wanted to purchase in period 1 but found the title out of stock, or they could just reflect the revealed preferences of consumers with idiosyncratic timing preferences. For example, a consumer could be purchasing the tape for a friend's birthday which occurs in week 25 . In estimation, I assume that consumers are just as happy purchasing these titles in period 2 , and I treat the quality of the sale in these cases as being no different from the quality of earlier sales of the same titles. This assumption is somewhat supported by examining prices over time.

Prices of rentals and sales by month are shown in Table 6 , which is also organized according to the pricing pattern used for a film's VHS release. Rentals of DVDs are slightly more expensive than VHS; there are no significant differences in the price of a rental according to whether or not a film was rental priced. This is somewhat surprising: the model predicts that lower costs of inventory should yield lower rental prices to consumers. It seems that 99-cent children's rentals, common in the eighties and nineties, are no longer found in the data (and for that matter, one might expect 99-cent DVD rentals). ${ }^{43}$ I say more about this in the discussion of retailer mark-ups later in the paper. Prices of rentals do not change after month 5, because I aggregate rental transactions that occur after week 21 and report the average price. Prices of used sales are also slightly higher for DVDs, and there are no significant differences between prices of used tapes based on whether or not rental pricing was used for a film's VHS release. Prices of new sales in period 1 differ significantly for rental priced VHS tapes. Average prices during the first five months (before sell-through re-pricing occurs) range from $\$ 89$ to $\$ 100$. In contrast, prices of new sales in period 2 (months 6 and higher) average between $\$ 18$ and $\$ 27$. For sell-through priced VHSs and all

\footnotetext{
${ }^{43}$ In the most recent update of this paper (Autumn, 2004), selected Hollywood Video and Blockbuster retailers have introduced just such a program.
} 
DVDs, prices of new sales in the second period are very similar to prices of new sales in the first period, although there is a small reduction in price over time.

Table 7 shows total activity levels in the data, as well as weighted totals. Most of the sales that occur in this population of stores are sales of used tapes. The weights applied to new sales are much larger, as I discuss in the estimation section. The ratio of total weighted sales to total weighted rentals across the four quadrants shows a higher overall level of weighted sales for DVDs compared to VHSs: 29.9 and 34.5 percent of rentals for DVDs versus 13.2 and 7.5 percent of rentals for the same titles on VHS format. Note that by comparing the different titles on the DVD format, one should get a sense of the importance of the endogeneity of the sell-through pricing decision. DVDs are priced the same for all titles, so the extent to which sell-through priced titles sell better on DVD than rental priced titles should be due to unobservable characteristics of the titles that make them relatively more desirable to own. This difference in the ratio of sales to rentals for these sets of titles is 4.6 percent for DVDs (34.5 versus 29.9 percent). Overall levels of DVD activity (including rentals) are higher for sell-through priced titles, but overall levels of VHS activity are higher for rental priced titles.

Titles sell less often on the VHS format. This presumably reflects a relatively higher quality attached to owning DVDs compared to VHS tapes, perhaps because of the increased durability or flexibility for playing the DVDs on laptops, etc. It could also reflect differences in taste for quality across the population of consumers adopting DVD versus VHS. The difference between rental priced titles and sell-through priced titles on the VHS format reflects both unobservable differences in the desirability of owning that lead to a sell-through or rental-pricing decision, as well as the effect of delaying sales of the rental priced titles. The difference here is quite large: sales total 13.2 percent of rentals for sell-through priced titles, compared to 7.5 percent of rentals for rental priced titles. The difference is due to both lower levels of rentals as well as higher levels of sales.

\section{$5 \quad$ Estimation and Results}

This section estimates the relevant demand and retailer parameters. Racall that in order to address the research questions of interest, one must first understand the factors that influence firms' price discrimination strategies: namely, the nature of demand, including product qualities and consumers' willingness to pay for quality. With estimates of these 
parameters in hand, one can seek to understand the pricing policies currently in place.

The patterns of sales and rentals shown in the last section provide motivation for the model of demand outlined earlier, in which products are vertically differentiated. ${ }^{44}$ In this section, I describe the necessary extensions of the demand specification, distributional assumptions, and sources of identification that are used in estimation. I use only demandside moment restrictions for the purpose of estimation. Supply-side information will be used to provide additional modeling as it becomes necessary in the counterfactual experiments, after confirming a reasonable fit of the model's parameters from estimation using only the demand-side restrictions.

\subsection{Estimation and Identification}

When estimating the model of demand in section 3, I include an additional product-purchase of a used tape-that has quality level $\delta_{u} \in\left(\delta_{r}, \delta_{\text {new }}\right)$ where $\delta_{\text {new }}$ takes the value $\delta_{s}$ if the title is sell-through priced, and takes the value $\delta_{s 2}$ if the title is rental priced. In other words, I assume that owning a used tape provides lower quality than owning a new tape, but higher quality than a rental (for a particular title). I adopt the simple two-period model from section 3 for two reasons. First, the pattern of rentals and sales in table 5 are generally consistent with a two-period model as a first-order approximation to the timing of rentals and sales in this industry. Second, the nature of pricing in this market has always been one in which products are either introduced immediately at one low price, or products are introduced at a high price and are subsequently re-priced once. Thus, the model is very much driven by the institutional details of the industry.

Empirically, a market is defined to be a zipcode-title-format triple. ${ }^{45}$ A market in this context includes three (or four) products: the rental of a title, or the purchase of a new or used tape of a title, on either the VHS or DVD format. Thus, conditional on which hardware they own, consumers decide whether to purchase or rent a given title in their local zipcode. I consider two time periods for rental priced titles: before and after sell-through re-pricing.

Note that the market definition implies that a studio acts as a monopolist for a particular

\footnotetext{
${ }^{44}$ While the pricing patterns provide strong evidence for vertical differentiation across rental, used, and new sales, the relative ranking of the outside good cannot be directly verified in the data. One could estimate alternative demand specifications, such as a logit, or a more flexible random-coefficients model (such as in Berry, Levinsohn and Pakes (1995) and Nevo (2000)) if the ranking of the outside good was of significant concern.

${ }^{45}$ For a discussion of the use of zipcodes to define geographic markets in this industry see Mortimer (2004).
} 
title, because I do not model competition across movies in the sample. An alternative market definition might include rentals and sales of other titles released during some defined window of time. ${ }^{46}$ The inclusion of competing titles, although a potentially attractive extension of the model, requires an alternative set of assumptions about the nature of competition over time, because movies are released in different weeks. In fact, studios attempt to avoid competing with each others' titles by choosing different release dates. For example, the 41 titles analyzed here are released across 108 weeks, so direct competition between titles is softened by the staggered release schedule. Competition between titles and the effect of rationing resulting from temporary inventory stockouts is also mitigated by the fact that demand is considered in aggregate over several months. Thus, a consumer may intertemporally substitute between two titles on any given visit to a rental store (selecting one over the other), but in aggregate over several months, the consumer may be observed to rent both movies.

Following the notation in Berry (1994), demand for rentals and purchases are derived based on the consumer utility functions in section 3, where the parameter $\alpha$ captures the marginal utility of income. I specify a flexible Weibull distribution for $\alpha$, with parameters $(\lambda, \rho)$, s.t. $\lambda, \rho>0$, and $\lambda \equiv \exp \left(Z_{m}^{\prime} \gamma\right)$, where $Z_{m}$ contains a constant term and the log of median income. The probability density function is given by $f(\alpha)=\rho \lambda \alpha^{(\rho-1)} \exp (-\lambda \alpha)^{\rho}$; the cumulative density function is given by $F(\alpha)=1-\exp (-\lambda \alpha)^{\rho}$. The predicted demand levels are calculated based on the distributional assumption for $\alpha$; thus, sales (or rentals) as a function of the model's parameters are:

$$
\begin{aligned}
& q_{s, m, j}=N \cdot\left(1-\exp \left(-\exp \left(Z_{m} \gamma\right)\left(\frac{\delta_{s, m, j}-\delta_{u, m, j}}{p_{s, m, j}-p_{u, m, j}}\right)^{\rho}\right)\right) \\
& q_{u, m, j}=N \cdot\left(\exp \left(-\exp \left(Z_{m} \gamma\right)\left(\frac{\delta_{s, m, j}-\delta_{u, m, j}}{p_{s, m, j}-p_{u, m, j}}\right)^{\rho}\right)+\exp \left(-\exp \left(Z_{m} \gamma\right)\left(\frac{\delta_{u, m, j}-\delta_{r, m, j}}{p_{u, m, j}-p_{r, m, j}}\right)^{\rho}\right)\right) \\
& q_{r, m, j}=N \cdot\left(\exp \left(-\exp \left(Z_{m} \gamma\right)\left(\frac{\delta_{u, m, j}-\delta_{r, m, j}}{p_{u, m, j}-p_{r, m, j}}\right)^{\rho}\right)+\exp \left(-\exp \left(Z_{m} \gamma\right)\left(\frac{\delta_{r, m, j}}{p_{r, m, j}}\right)^{\rho}\right)\right) \\
& q_{0, m, j}=N \cdot\left(\exp \left(-\exp \left(Z_{m} \gamma\right)\left(\frac{\delta_{r, m, j}}{p_{r, m, j}}\right)^{\rho}\right)\right)
\end{aligned}
$$

where the definition of market size, $N$ is defined appropriately according to the auxilliary data discussed in section 4. For each title, we observe sales and rentals in over 2,000

\footnotetext{
${ }^{46}$ One benefit of aggregating sales and rentals is that this mitigates cross-titles substitution caused by stockouts and rationing. In other words, if one used weekly data, the effect of stocking out of a particular title would potentially affect a title's rentals. By aggregating all of a title's weekly rentals, I allow for intertemporal substitution, so that consumers who may be stocked-out in one week can rent the title in a later week.
} 
geographic markets; the additional subscripts denote variation across titles and geographic market areas. Thus, $\delta_{r, m, j}$ represents the quality level of a rental of title $j$ in market $m$. Furthermore, suppressing additional notation, $\delta_{r, m, j}, \delta_{u, m, j}$ and $\delta_{s, m, j}$ are assumed to represent the quality levels of the appropriate format for title $j$, so that $\delta_{r, m, j}$ takes the value $\delta_{r, m, j}^{v}$ and $\delta_{r, m, j}^{d}$ for VHS and DVD formats respectively.

I assume that purchases of new sell-through priced VHS tapes and DVDs occur in period 1. However, if a title is rental priced on the VHS format, the sales share is divided between sales in the first period and sales in the second period. In this case, new sales are predicted by the model's parameters as:

$$
\begin{aligned}
q_{s, m, j} & =N \cdot\left(1-\exp \left(-\exp \left(Z_{m} \gamma\right)\left(\frac{\delta_{s, m, j}-\delta_{s 2, m, j}}{p_{s, m, j}-p_{s 2, m, j}}\right)^{\rho}\right)\right) \\
q_{s 2, m, j} & =N \cdot\left(\exp \left(-\exp \left(Z_{m} \gamma\right)\left(\frac{\delta_{s 2, m, j}-\delta_{u, m, j}}{p_{s 2, m, j}-p_{u, m, j}}\right)^{\rho}\right)+\exp \left(-\exp \left(Z_{m} \gamma\right)\left(\frac{\delta_{u, m, j}-\delta_{r, m, j}}{p_{u, m, j}-p_{r, m, j}}\right)^{\rho}\right)\right)
\end{aligned}
$$

where $p_{s 2, m, j}$ is the price of a sale in the second period. Using the distributional assumptions for $\alpha$, I can rewrite equation 9 in terms of the quality parameters. This produces local estimates of movie quality which are of the form:

$$
\delta_{r, m, j}=p_{r, m, j}\left[-\ln \left(s_{0, m, j}\right) \cdot \exp \left(-Z_{m} \gamma\right)\right]^{-(1 / \rho)}
$$

for a rental; similar expressions are solved recursively for the quality of used and new purchases $\left(\delta_{u, m, j}\right.$ and $\left.\delta_{s, m, j}\right)$. Once again, the quality parameters take values of $\delta_{r, m, j}, \delta_{u, m, j}$ and $\delta_{s, m, j}$ that are format-specific (VHS or DVD). Local market shares are denoted by $s_{0, m, j}$, etc., and are defined as $\frac{q_{0, m, j}}{N}$ using the relevant value of $N$ according to equation 8 . The quality parameters for rental priced VHS titles are solved similarly to incorporate period 1 and period 2 sales.

The market-specific quality of a title-use-format is decomposed as follows:

$$
\begin{aligned}
& \delta_{r, m, j}=\delta_{r, j}+X_{m} \beta_{j}+\xi_{r, m, j}, \text { for rentals, and } \\
& \delta_{s, m, j}=\delta_{s, j}+X_{m} \beta_{j}+\xi_{s, m, j}, \text { for new sales, }
\end{aligned}
$$

and the quality of used tapes or second-period sales are similarly defined. The term $\delta_{r, j}$ denotes the national average quality of a rental of the movie, and $\delta_{s, j}$ denotes the national average quality of a purchase. The term $X_{m} \beta_{j}$ denotes the market-specific quality of all uses of title $j$ in market $m$ and allows for horizontal differentiation across geographic markets 
for different movie titles on the basis of observables. Note that the effect of any observable $X_{m}$ is allowed to differ across movie titles. For example, movie $j$ may be more valuable both as a rental and as a purchase in market $m$ because it appeals to local demographics. Local demographic shifters $\left(X_{m}\right)$ include the percent of the area that is suburban, store size, the percent of families who are married with kids, and the local DVD penetration rate, which is measured at the state level in each month. Finally, $\xi_{\cdot, m, j}$ captures the unobserved quality of a title-use-format in market $m$. For example, a rental of title $j$ may be more valuable in market $m$ because of unobservable promotions or community events. Prices vary by market $\left(p_{r, m, j}\right.$, etc.) and also apply separately to VHS and DVD formats (thus, they have a suppressed $v$ or $d$ superscript similar to the quality variables).

\section{Instruments}

The $\xi_{\cdot, m, j}$ terms contain all unobserved characteristics of a use (such as rental or sale) of title $j$ in market $m$. The unobserved attributes may be correlated with the local retail price, $p_{\cdot, m, j}$, and any such correlation will bias the estimate of $\gamma$. A valid instrument for price must be uncorrelated with the unobserved attributes of the good, but still correlated with price. Thus, researchers often use an instrumental variable that is correlated with costs, or else correlated with competitive conditions from the supply side, as these measures affect price, but are uncorrelated with tastes for unobserved features of the product. In this case, we need to instrument for all three uses of the good: rentals, used sales, and new sales.

The variable cost of a rental is one candidate instrument for rental price. This cost is calculated by dividing the wholesale price of a tape by the number of rentals per tape for that store-title pair. The wholesale price assumes a 40 percent discount off the observed suggested retail price of each videocassette tape or DVD. ${ }^{47}$

Thus, variation in retailers' average costs of rentals (for a given title) arises because of variation in the number of rentals per tape: some retailers purchase 10 tapes and produce 100 rentals from them, while others purchase 10 tapes and produce 200 rentals from them. Unfortunately, constructing this variable requires an ex-post measure of rental demand (through division by $q$ ) and so, by construction, the instrument is correlated with tastes for

\footnotetext{
${ }^{47}$ The wholesale discount figure was obtained through interviews with studio executives and video retail owners. Other discounts (such as volume discounts, bundling discounts, or other 'copy-depth' programs may also apply. I assume that retailers pay the usual wholesale price when reselling tapes, but get a 20 percent discount on rental inventories that are acquired under rental-pricing contracts. These figures were derived from consultations with industry executives; the results are robust to reasonable alternative assumptions on these costs (such as the removal or extension of the additional 20 percent discount.)
} 
unobserved attributes of the local rental use of that title, and thus invalid. Two options are available: first, one could choose to not instrument for rental price. Rental price does vary across titles within a retail location, but the extent of the variation is smaller than that across retail locations. Furthermore, one could argue that there is sufficient stickiness in price across titles at a retail location that instrumenting for price is not necessary.

Alternatively, one could construct an expected average cost of a rental of a title at a store by essentially bootstrapping the cost of other similarly-priced titles on the same format, where "similarly priced" refers to rental pricing or sell-through pricing. For example, of the 12 titles released under rental-pricing terms on the VHS format, the expected average cost of a rental at store $\mathrm{A}$ of title 12 is measured by the average cost of a rental at store $\mathrm{A}$ of titles 1 - 11. Cost measures for titles 1 - 11 are constructed in a similar fashion. This measure captures common cost components that store A faces for rental-priced titles on the VHS format, but preserves the title-level variation within the store. In order for the expected average cost of a rental to be a valid instrument, this variation cannot be under the control of the retailer. One possibility is that retailers cannot anticipate the number of rentals that each unit of inventory will produce. ${ }^{48}$ Another possibility is that retailers-even if they can anticipate a lower or higher inventory usage rate-cannot control this rate for an individual title, conditional on the cost of inventory. ${ }^{49}$ Both assumptions seem reasonable, especially for the large 'blockbuster' titles analyzed here.

I estimate demand and calculate the results from counterfactual experiments using both methods (not instrumenting for the rental price, and using the expected average cost of a rental). In the analysis that follows, I present results that use the expected average cost of a rental as an instrument for rental price. Not instrumenting for the rental price yields results that are qualitatively the same throughout the analysis. ${ }^{50}$

Instrumenting for used and new sales is more straightforward. For used sales, I use the total rental inventory that the retailer ordered for title $j$ less one unit, which is by definition his available supply of the used product. For new sales, the average cost to the retailer of title $j$ depends only on the wholesale price, which does not vary across retailers. Therefore, I interact the wholesale price paid by retailers with the observed competitive conditions

\footnotetext{
${ }^{48}$ See Mortimer (2004) for a similar treatment of this variable, which allows for uncertainty from the retailer's point of view in $\tau$.

${ }^{49}$ Note that competition in the retail market will also set $\tau$ if consumers value earlier availability of a movie rental.

${ }^{50} \mathrm{I}$ omit these results in the interest of brevity, but they are available upon request.
} 
in their local market, which consist of three variables: the number of video stores in the same zipcode, and the numbers of Blockbuster and Hollywood Video store locations in the zipcode.

Having described the instruments, one can now use equation 12 to form moment conditions:

$$
E\left(W^{\prime} \xi_{r, m, j}\right)=0
$$

where $W$ includes $Z_{m}$ and the instrumental variables (i.e., retailer costs). The parameters to be estimated are: $\theta \equiv\left(\delta_{r}, \delta_{u}, \delta_{s}, \delta_{s 2}, \beta, \gamma\right)$. The parameters $\delta_{r}, \delta_{u}$, and $\delta_{s}$ are all vectors of length $J$ (the number of titles), while $\delta_{s 2}$ has length equal to the number of rental priced titles.

Estimation proceeds using generalized method of moments, choosing $\theta$ to minimize

$$
\hat{\theta}=\operatorname{argmin}\left(\sum_{i} \psi\left(\theta, W_{i}\right)\right)^{\prime} A\left(\sum_{i} \psi\left(\theta, W_{i}\right)\right) .
$$

where $\psi\left(\theta, W_{i}\right)$ is the set of moment conditions, $i$ is now used to denote format-title-use observations, and $A$ is a weight matrix chosen to minimize variance according to Hansen (1982). Estimation is simplified by using a two-step procedure. I first guess values for the $\delta$ and $\beta$ vectors, then minimize the objective function over values of $\gamma$ and $\rho$. Given the new values of $\gamma$ and $\rho$, I construct fitted values of $\delta_{\cdot, m, j}$ 's, which I can regress on title-use-format dummies and the $X_{m}$ 's to recover new estimates of the $\delta$ and $\beta$ vectors. I iterate this procedure until convergence.

The parameters of the distribution of $\alpha(\gamma$ and $\rho)$ are identified from variation in the instruments, as well as variation in income across geographic markets, while the quality parameters are identified off of title-use-format dummies and local demographic characteristics. As utility functions are ordinal, rather than cardinal, I normalize the value of the outside good for movie 1 on the VHS format such that $E\left(X_{m} \beta_{1}\right)$ is equal to a constant. ${ }^{51}$

\footnotetext{
${ }^{51}$ I calculate the value of $E\left(X_{m} \beta_{1}\right)$ by setting $\alpha=1$, computing the $\delta_{\cdot, m, j}$ 's, and then regressing $\delta_{,, m, j}$ on use dummies and $X_{m}$. The vector $\beta_{1}$ from this regression (i.e., the value of the beta vector for title 1 , on VHS) was then used to normalize the outside good in each market for title 1 . This was done to preserve geographic variation in the normalization for title 1 . Normalizing the value of $\beta_{1}$ to be zero would give the same value of the outside good for all geographic markets. My method normalizes $\beta_{1}$ to be equal to some vector of non-zero constants.
} 


\subsection{Estimation Results}

Table 8 provides estimates of the parameters of the model. Rather than report 41 sets of quality parameters (one set for each title), I report means of the parameter estimates for each of the four format-pricing types (i.e., VHS and DVD formats, based on whether the VHS format was rental priced or sell-through priced.)

The $\beta$ parameters affect the 'local quality' or local taste for movies, across all uses of a title. Larger stores are located in neighborhoods where a higher overall utility exists for movie watching regardless of format (the average $\beta$ associated with store size is positive). A higher proportion of "families that are married with children" is associated with a lower overall utility of movie watching on the VHS format, but with a higher overall utility of movie watching on the DVD format although this varies by movie and genre. Surburban areas are estimated to receive lower relative utility on the DVD format compared to their non-suburban counterparts. This effect is often not statistically significantly different from zero. DVD hardware penetration rates are strongly correlated with tastes for movie watching. When examining the market for movies on the VHS format, neighborhoods with higher DVD penetration are estimated to have higher overall utility from movie consumption. In contrast, neighborhoods with higher DVD penetration are estimated to have lower overall utility from movie consumption on the DVD format. This is consistent with an adoption pattern of DVD hardware in which high-value consumers adopt early. Finally, the parameters of the distribution of $\alpha$ indicate that neighborhoods with higher median income are associated with a higher willingness to pay for movies on tape or DVD $\left(\gamma_{1}=1.06\right)$.

The quality parameters indicate that DVD is typically of higher average quality than VHS. People in the market for DVDs are estimated to have higher utility from movie watching than people in the market for VHS for the set of titles that are sell-through priced on the VHS format, based on the average value of $X \beta$. For the set of titles that were rental priced on the VHS format, the average values of $X \beta$ are lower for the DVD format. The rental-use dummies are slightly lower for the DVD format compared to VHS, while the used and new sale use dummies are higher for the DVD format (based on the average value of $\delta_{\cdot, j}$ 's). The lower average quality on the DVD format, compared to the VHS format is primarily driven by lower quality estimates for children's titles. ${ }^{52}$ The set of movies for

\footnotetext{
${ }^{52}$ Anecdotally, trade press articles cite the ease of use of the VHS format for children as one source of this difference, because VHS tapes can be inserted into a machine and automatically played without the need to press any additional buttons.
} 
which the VHS format was rental priced are of average higher quality than the set of sellthrough priced movies for both formats. The decay rate for the quality of a purchase is estimated as the ratio of the quality of a purchase in the second period and the quality of a purchase in the first period for rental priced VHS titles, and is 0.89 on average.

Table 8 also reports values for the parameters $\tau$ and $\mu$, which are essentially backed-out from the data directly. The $\tau$ parameter is the ratio of rentals to inventory, and differs considerably across the two pricing regimes. Table 8 indicates that VHS inventory is used more intensively for titles that are rental priced, producing 23.7 rentals per tape compared to 16.9 rentals per tape for sell-through priced titles. DVDs show almost no difference in the rental technology across the two sets of titles, producing 15.6 and 15.3 rentals respectively. The $\mu$ parameter is estimated as the difference between the observed retail price, and the observed variable cost of the rental. Retail mark-ups are higher for the sell-through priced VHS titles and for DVDs: around $\$ 2$ compared to $\$-0.03$ for rental priced titles on the VHS format, and between $\$ 0.38$ and $\$ 0.90$ for both sets of titles on the DVD format. Sales markups by retailers are around $\$ 40$ in the first period for rental priced VHS, but are around $\$ 4$ after re-pricing. Mark-ups in the first period for sell-through priced VHS and titles on the DVD format range from $\$ 8$ - $\$ 10$. The retailer mark-up on sales of used tapes is assumed to be equal to the price, with no proceeds going to the upstream firm. ${ }^{53}$

\section{Counterfactual Experiments and Welfare Analysis of Copyright Law}

Using the estimated demand model I examine the welfare implications of price discrimination under current U.S. and E.U. copyright law in three steps. First, I examine the welfare implications of the two pricing regimes (rental pricing and sell-through pricing) currently observed under U.S. copyright law. Second, I examine the welfare implications of a shift to E.U. copyright law allowing for third-degree price discrimination. Third, I examine the future optimal DVD pricing strategy under U.S. copyright law and the welfare implicatons of E.U. copyright law as DVD hardware adoption continues to supplant VCRs in the future.

In order to undertake the first step, I use the estimated parameters in table 8 to predict market shares, variable profits for studios and retailers, and consumer surplus assuming that studios choose the price or prices that maximize their profit on each title. I then recalculate market shares, variable profits and consumer surplus under the assumption that studios

\footnotetext{
${ }^{53}$ Both $\tau$ and $\mu$ need to be modeled in any counterfactual analyses. I discuss this in the next section.
} 
adopt the "other" pricing regime in each of the four groups of title-format pairs, allowing for the studio's optimal price under the alternative regime. That is, I examine the outcomes if rental priced titles were instead sell-through priced and vice versa. This counterfactual yields the welfare implications of alternative pricing strategies under U.S. copyright law.

To examine the welfare implications of a switch to E.U. copyright law, I perform the same calculation as above, but allow studios to directly charge different prices in the rental and sales markets. In priciple, one might also be interested in the effects of a policy that uses both market-segmentation and intertemporal price discrimination. Although studios are not observed doing this in the E.U., there would be no legal restrictions barring it under the E.U. copyright law. Finally, for step three I predict whether or not sell-through pricing of DVD will continue in the future under U.S. copyright law as DVD hardware adoption continues, and what implications if any this would have on the welfare effects of switching to E.U. copyright law. To accomplish this, I perform the same calculations as above, but apply the DVD coefficients on local quality to the VHS market. The exercise supposes that continued adoption of DVD hardware will expand DVD rental and sales activity into markets that currently serve only VHS users, but that the DVD quality parameters do not change. The point of this exercise is to estimate the effects for firms and consumers of price discrimination in the context of the evolution of a new technology.

There are several explanations for the current pricing of titles on the DVD format. The DVD format may represent a permanent shift in the nature of the 'packaged good' movie product. If the quality of renting or buying, or the relative quality of these uses, is much higher for the DVD format, changes in the distribution of consumer tastes are unlikely to affect the optimal pricing strategy. As described in the previous section and in table 8, it does appear to be the case that there is a larger difference in the quality of buying versus renting for the DVD format than for the VHS format. The change in pricing should lead to a decline of the rental industry and a very different form of distribution for this segment of the motion picture industry. Another explanation is that the current pricing strategy of DVDs functions as an introductory pricing mechanism. In this case, high-value consumers, and not the relative difference in purchasing and renting qualities, drive the pricing decision. Thus, changes in the distribution of consumer tastes that results from hardware evolution should lead to a DVD pricing strategy that mimics the strategy used for VHS and preserves the heavy reliance upon a rental market. Yet another possible explanation for the different 
pricing of DVDs is that the rate of decay of sales quality is different under this format. If this rate of decline in quality is much faster for DVDs, sell-through pricing would be optimal.

\subsection{Additional Modeling for Counterfactual Exercises}

Retailer Markups and Inventory Use

The pricing strategies outlined here are non-nested cases: depending on the values of the structural parameters, a firm might prefer sell-through pricing to rental pricing, or vice versa. Although rental pricing involves price discrimination and sell-through pricing does not, price discrimination under rental pricing is achieved only at the cost of destroying some of the value of the sales product through the decay of quality. Similarly, a firm might prefer rental pricing to market segmentation (or "EU pricing"), or vice versa, since EU pricing is assumed to not give the firm the ability to discriminate intertemporally. The only nested pricing strategy is that a firm should always be able to replicate the results of sell-through pricing under an EU pricing strategy, since the two prices set under EU pricing can always be chosen to mimic a sell-through pricing strategy. These predictions are true holding all parameter values fixed. However, as already noted, the values of the retailer-level parameters differ considerably across titles according to pricing type. Rental priced VHS titles have much lower retailer mark-ups empirically than sell-through priced titles (a lower $\mu_{r}$ ), and they are used more intensively (a higher $\tau$ ).

There are two choices for how to handle changes in $\mu$ and $\tau$. On one hand, one could write down a model of retailer competition in which $\tau$ and $\mu$ are determined endogenously. One challenge with this approach is that many of the observable competitive conditions at the retail level do not change across pricing types.

Alternatively, one could adopt a less complete model of retailer competition, but use the rich structure of the data to predict changes in $\mu$ and $\tau$ empirically under counterfactual upstream pricing strategies. The benefit of this approach is that it retains the focus on the upstream pricing decisions and allows for considerable flexibility within the current set of prices that are observed. It also allows for flexibility across retailers that differ according to unobservable characteristics, but which have the same observable characteristics. The main drawback to this approach is that, while it may give quite accurate predictions about changes in $\mu$ and $\tau$ for pricing contracts that are observed, it is less informative about 
changes in $\mu$ and $\tau$ for prices for which we have no observations. In other words, out-ofsample predictions are more constrained. I adopt the second method. The reduced-form model for changes in $\mu$ and $\tau$ that result from new pricing strategies at the upstream level is as follows.

For $\mu$, I assume that each retailer receives the average markup observed for its "other" priced movies when examining the effects of the "other" pricing strategy. For example, for a rental of title $j$ at store $k$, I regress:

$$
\mu_{r j k}=\mu_{0, r k} R P+\mu_{1, r k} S T P+\epsilon_{r j k}
$$

Then, for retailer $k$, I use $\hat{\mu}_{0, r k}$ for counterfactual exercises examining outcomes of a rental pricing strategy for titles that were actually priced for sell-through. Similarly, I use $\hat{\mu}_{1, r k}$ for counterfactual exercises examining outcomes of a sell-through pricing strategy for titles that were actually rental priced. An analogous approach identifies markups of sales. Thus,

$$
\mu_{s j k}=\mu_{0, s k} R P+\mu_{1, s k} S T P+\zeta_{s j k}
$$

gives counterfactual markups for sales. In addition to modeling retailer markups, I allow for a change in the intensity of inventory use under the counterfactual pricing regime. This is due to the difference in the cost of a tape for downstream retailers. In a method analogous to that used for retailer markups, I regress

$$
\tau_{j k}=\tau_{0, k} R P+\tau_{1, k} S T P+\eta_{j k}
$$

to give counterfactual inventory use. ${ }^{54}$ One could incorporate other variables in these predictions to allow for a smoother mapping over prices. For example, one could regress $\mu$ and $\tau$ on pricing indicators as well as on actual wholesale prices. In all of these methods, I assume that the regressors are orthogonal to the error terms.

\section{Second Period Quality}

In addition to retailer parameters, the quality of a second-period purchase must be estimated for sell-through priced titles, since I do not have any data on actual second-

\footnotetext{
${ }^{54}$ I have also performed a number of robustness tests, such as calculating the average increase in inventory use for the two pricing regimes, and applying that to each store's actual $\tau$ for each title. The average increase is around three (i.e., stores produce three times as many rentals from each tapes for rental-pricing titles, compared to sell-through priced titles). The results are not affected in any meaningful way.
} 
period purchases for those titles that would identify this quality level directly. The results in table 9 use an estimate of second-period quality that is constructed as follows. The average difference between the first-period new purchase quality and the used purchase quality is estimated for each genre from the 12 rental priced titles in the top panel. ${ }^{55}$ I then calculate the percentage split represented by the second-period purchase quality for these titles, and apply that percentage to the sell-through priced titles in the second panel. For example, if rental-priced dramas have average used, period 2, and period 1 qualities of 1 , 1.5 , and 2, respectively, and a sell-through priced drama (say, title $j$ ) has used and period 1 qualities of 2 and 4 , then the period 2 quality assigned to title $j$ is 3 . I have tried several robustness tests of this assumption, and none of them change the results in any meaningful way. ${ }^{56}$

\section{Durable Goods and Used Markets}

Finally, the demand for used tapes highlights an important issue for producers of durable goods. I assume in the counterfactual exercises that the market for used tapes is constrained by the level of inventory purchased by retailers. Thus, I assume that retailers can only sell used tapes up to the level of their inventory, less one tape to keep for future rental business. In many cases, this leads to rationing of used tapes. This effect is quite interesting, as it highlights the importance of price discrimination in markets for durable goods where an upstream firm does not control the second-hand market.

\subsection{Welfare Analyses}

The results of the counterfactual exercises are contained in tables 9 - 11. I start with table 9 , in which the first two columns give actual and estimated market shares for the VHS format. The table is divided into two panels, according to whether or not a title's VHS release was rental or sell-through priced. The first column lists actual prices, market shares, and variable profits for upstream and downstream firms. The reported profits are the average variable profits for a title, assuming that mark-ups and prices in the unobserved stores in each market are the same as the mark-ups and prices I do observe. Actual market shares are around 25 to 29 percent for rentals of titles on VHS. Column 2 of table 9 solves for

\footnotetext{
${ }^{55}$ For children's titles, I used PG-rated "family" movies, which are primarily directed at the children's market.

${ }^{56}$ It is straightforward to bound this parameter, because the second-period quality is presumably greater than the used quality and less than the period-one new quality.
} 
the optimal monopoly price, given the parameter values. In the top panel, covering rental priced VHS titles, the optimal price is estimated to be slightly lower than the actual price for this set of titles, with slightly higher profits to the studio and to retailers. Overall, the estimated prices indicate a reasonably good fit to the data. In the bottom panel, covering sell-through priced VHS titles, estimated prices and market shares are quite close to the actual, implying that the demand model is predicting the data quite well. Subsequent comparisons will be to these results in column two.

Column 3 of table 9 gives predicted market shares and profits under the "other" pricing regime. For the first panel of table 9, which contains rental-priced movies, this corresponds to the adoption of sell-through pricing. I again solve for the optimal wholesale price. Markups and inventory use are modeled as described in the previous section. At these parameter values, the use of sell-through pricing results in a 15 percent reduction in profits for the studio. Retailers would be 10 percent better off under this pricing regime, and consumers would be worse off under this scenario, with consumer surplus falling roughly 22 percent. In the panel of table 9 that covers sell-through priced titles, the third column corresponds to counterfactual outcomes under rental pricing. Both studios and retailers are worse off under rental pricing for this set of titles. This is consistent with reports in industry trade journals and interviews about the expected effects of rental pricing for such movies. Consumers are better off. Note the effects of rental pricing strategies to limit the size of the used market. Studios receive no revenues from these sales, and price new tapes in order to shrink the supply of used tapes under the rental pricing strategy. The shrinking of this market also occurs because video stores are assumed to use inventories more intensively under rental pricing, thus carrying smaller inventories that can subsequently be re-sold.

Column 4 of table 9 gives results under market segmentation, similar to the pricing policies followed by these same studios in countries with EU-type copyright laws. Under this counterfactual, studios are allowed to charge different prices to retailers and consumers on the first day of a movie's release to the video market, but I assume they do not engage in intertemporal price discrimination. I adopt parameter values of $\mu_{r}$ and $\tau$ that are appropriate to rental pricing in this exercise. I estimate that market segmentation makes studios and retailers worse off compared to rental pricing in the first panel. Consumer surplus decreases by 15 percent. Column 4 in the second panel shows a positive effect for studios under EU-type pricing, although retailers receive lower profits than they would have under 
rental-pricing and consumers are worse off.

Table 10 provides the same results for the DVD format. The comparison between the first two columns indicates a good fit of the model. Results of the experiment of adopting rental pricing for DVDs are shown in column three. Studios and retailers are estimated to be worse off under rental pricing for both groups of titles, as are consumers. Column four allows for EU-type pricing. Studios are estimated to increase their profits by about 5 to 7 percent under this pricing regime compared to the current sell-through pricing strategy. Consumers also benefit significantly under this policy. On the other hand, the use of market segmentation is estimated to make retailers worse off. Anecdotally, the average predicted prices under this scenario ( $\$ 40$ for retailers and $\$ 24$ for consumers for the set of sell-through priced titles) are very close to some actual prices charged for recent sell-through priced DVD releases in the U.K.. For example, Garfield - The Movie, with U.S. theatrical boxoffice receipts of $\$ 75$ million, was released in the U.K. recently at prices of $£ 15.99$ and $£ 11.99$, or $\$ 30.74$ and $\$ 23.05$, for retailers and individuals respectively.

Table 11 examines the outcomes among current VHS participants under the assumption that everyone in the VHS market eventually adopts DVD technology. The outcomes are calculated by replacing the product quality parameters for each title-use pair under the VHS format with the quality parameters for the same title-use appropriate to the DVD format. Retailer mark-ups are assumed to be unchanged compared to the values in the equivalent columns in table 9 , as are consumers' tastes for all uses of a movie (i.e., the $\beta$ parameters). Production costs for the studio are adjusted to reflect production costs for DVDs. The results in table 11 indicate that as the VHS market adopts DVD technology, rental-pricing becomes a more profitable strategy for the studio, compared to sell-through pricing. Despite the higher estimated quality of the DVD technology for owning compared to renting movies, the population that was using VHS technology in 2000 and 2001 differs from their DVD counterparts in the overall utility that it receives from watching movies (the $\beta$ 's). As a result, studio profits are estimated to be 24 percent higher under a rental-pricing strategy for the group of titles that were rental priced on VHS. On the other hand, studio profits are estimated to be 5 percent lower under a rental-pricing strategy for titles that were sellthrough priced on VHS. Retailers are worse off under the rental pricing regime than they would be under continued sell-through pricing policies, while consumers are made better off by the adoption of rental pricing. Market segmentation, or EU-style pricing, leads to 
higher studio profits than the profits expected with no price discrimination for both groups of titles. EU pricing also leaves retailers with lower profits than they would have earned under a sell-through pricing regime, while consumers benefit from a shift from sell-through pricing to EU pricing.

\section{Conclusion}

Firms respond strategically to the legal restrictions imposed upon them and the technologies they face, and consumers may be made better or worse off by these actions. As a result, giving additional control to a copyright holder may increase or decrease consumer surplus, and may also affect producer surplus for firms that use copyrighted goods as inputs (e.g., retailers). To identify factors influencing firms' optimal responses to U.S. copyright law, I empirically examine the outcomes of two pricing strategies used by firms for products that are identical in content, but distributed via an old established technology and a new emerging technology. Using a new dataset covering the distribution of movies on VHS and DVD formats, I find that firms consistently choose the more profitable pricing strategy across titles and formats.

I address three issues. First, I examine the welfare effects of the current price discrimination strategies used by firms in the U.S., and find that intertemporal price discrimination benefits copyright holders, but generally harms retailers. Consumer welfare is highest under the current price discrimination strategies in use; thus, for some titles, intertemporal price discrimination benefits consumers, while for other titles, consumers are made worse off by this form of price discrimination. Second, I estimate the welfare effects of an alternative form of copyright protection currently used in the E.U., allowing for the price discrimination strategy that would be optimal under that alternative. I find that price discrimination under this law tends to benefit studios and consumers at the expense of retailers, although studios are not better off for the set of movies that are currently intertemporally priced, and consumers do not benefit on the VHS format. Third, I consider the potential future effects of current and alternative copyright laws as firms respond to continued adoption of the DVD format and changes in the composition of DVD owners over time. I find that E.U.-style copyright protection allows for a more profitable pricing strategy by copyright holders on some titles, and that consumers benefit when this price discrimination strategy is chosen. 
Future research could examine the effects of intertemporal price discrimination in conjunction with revenue-sharing contracts. Such contracts were widely used for rental priced movies on the VHS format in the late 90 s, and could affect social welfare in future if intertemporal price discrimination were adopted for DVDs. Understanding the effects of pricing strategies in a simpler setting provides a foundation for analyses of more complicated supply contracts. If intertemporal price discrimination is profitable in the absence of non-linear contracts, the use of such contracts should make it even more attractive for copyright holders. By reducing some of the inefficiencies of intertemporal price discrimination, revenue-sharing may help to mitigate welfare losses due to copyright restrictions. 


\section{Appendix A: Optimal Price Discrimination Strategies}

For the cases outlined in section 3, one can estimate prices, market shares (for the purchase and rental products of a title), firm profits, and consumer surplus if the parameters $\left(N, \tau, c, \delta_{s}, \delta_{s 2}, \delta_{r}\right)$ and any parameters of the distribution of $\alpha$ are known (along with retail mark-ups, which we have so far been assuming to be zero). To provide a simple example of the upstream firm's pricing decision, I solve the firm's profit-maximization problem over a range of parameter values and provide a graph showing the values over which rentalpricing or sell-through pricing strategies are optimal. For this example, I assume that $1 / \alpha$ has a Weibull distribution with parameters $(\lambda, \rho)$ and retailer mark-ups are zero (i.e., $\left.\mu_{r}=\mu_{s}=0\right)$. I assume there is a single upstream firm and a single, price-taking retailer. I also assume $N=1, c=2, \delta_{s}=1.6$, and $\rho=2.9$. I solve for the optimal pricing strategy over a range of values for $\lambda$ and $\delta_{r}$ assuming that the upstream firm effectively cannot use third-degree price discrimination. I consider a few alternative assumptions about the parameters $\tau$ and $\delta_{s 2}$, which are discussed shortly. ${ }^{57}$ The values of $\lambda$ that I consider range from 0.17 to 0.40 , implying a mean value of $1 / \alpha$ of 1.1 to 0.23 , respectively for the given value of $\rho$. The values of $\delta_{r}$ that I consider range from $1 / 7$ th of the value of owning to $2 / 3$ rds of the value of owning. ${ }^{58}$

Results are shown in figure 1 for three alternative specifications of $\tau$ and $\delta_{s 2}$. The area down and to the left of each line represents the values of $\lambda$ and $\delta_{r}$ for which the upstream firm prefers rental pricing to sell-through pricing. Starting with the solid line (closest to the lower left-hand corner), I show the results when $\tau=20$ and $\delta_{s 2}=0.90 \delta_{s}$. When the relative quality of renting versus owning is high (so that consumers get a large part of the value of a movie by seeing it one time), rental-pricing is preferred. For a "high enough" $\delta_{r}$ (relative to $\delta_{s}$ ), rental-pricing is preferred over a large range of $E(1 / \alpha)$. However, as $E(1 / \alpha)$ becomes large, rental-pricing is no longer preferred. When the market has many low-value consumers, or when renting is a relatively high-quality good compared to owning, rental-pricing is the firm's most profitable strategy. On the other hand, when the value of

\footnotetext{
${ }^{57}$ In the empirical work, I relax many of these modeling assumptions; for example, I allow for greater variation in $\tau$, and I estimate retailer mark-ups.

${ }^{58} \mathrm{I}$ show results for discrete changes in $\lambda$ (increments of 0.1 ) and $\delta_{r}$ (it decreases from $\delta_{s} / 1.5$ to $\delta_{s} / 7.0$ in increments of 0.5 in the denominator).
} 
owning is a large multiple of the value of renting (perhaps because consumers watch the movie many times), a sell-through strategy is preferred. This accords well with the casual evidence that firms nearly always use sell-through pricing strategies for children's movies, and Blockbuster hits.

The next closest dotted line in figure 1 shows the parameter values for which rentalpricing is preferred when inventories are used differently under the two pricing strategies. Retailers are still assumed to have no mark-ups for this simple example, but I allow for the fact that inventories may be used more intensively when a movie is rental priced. As this is an empirical regularity in the industry, I assume that sell-through priced movies produce 20 rentals from each tape, while rental priced movies produce 30 rentals from each tape. There are two potential effects here: one is that the constraint on the relative price of a rental, compared to the price of a purchase, differs as a function of $\tau$. The other is that the cost of producing a rental is lower. Whether or not different values of $\tau$ make rental or sell-through pricing more attractive is essentially an empirical question. In this example, there is a slightly wider range of parameters over which the firm will choose rental-pricing. Finally, in the outermost dotted line, I show the results when $\tau$ differs in the same way as above, but $\delta_{s 2}=0.95 \delta_{s}$ rather than $0.90 \delta_{s}$. More patient consumers (a higher $\delta_{s 2}$ ) results in rental pricing being preferred over a larger set of values for $\lambda$ and $\delta_{r}$ : if consumers are more patient, there is not as much to lose by delaying the introduction of the good to the purchase market.

Figure 1: Optimal Pricing Strategies for Simulated Parameter Values

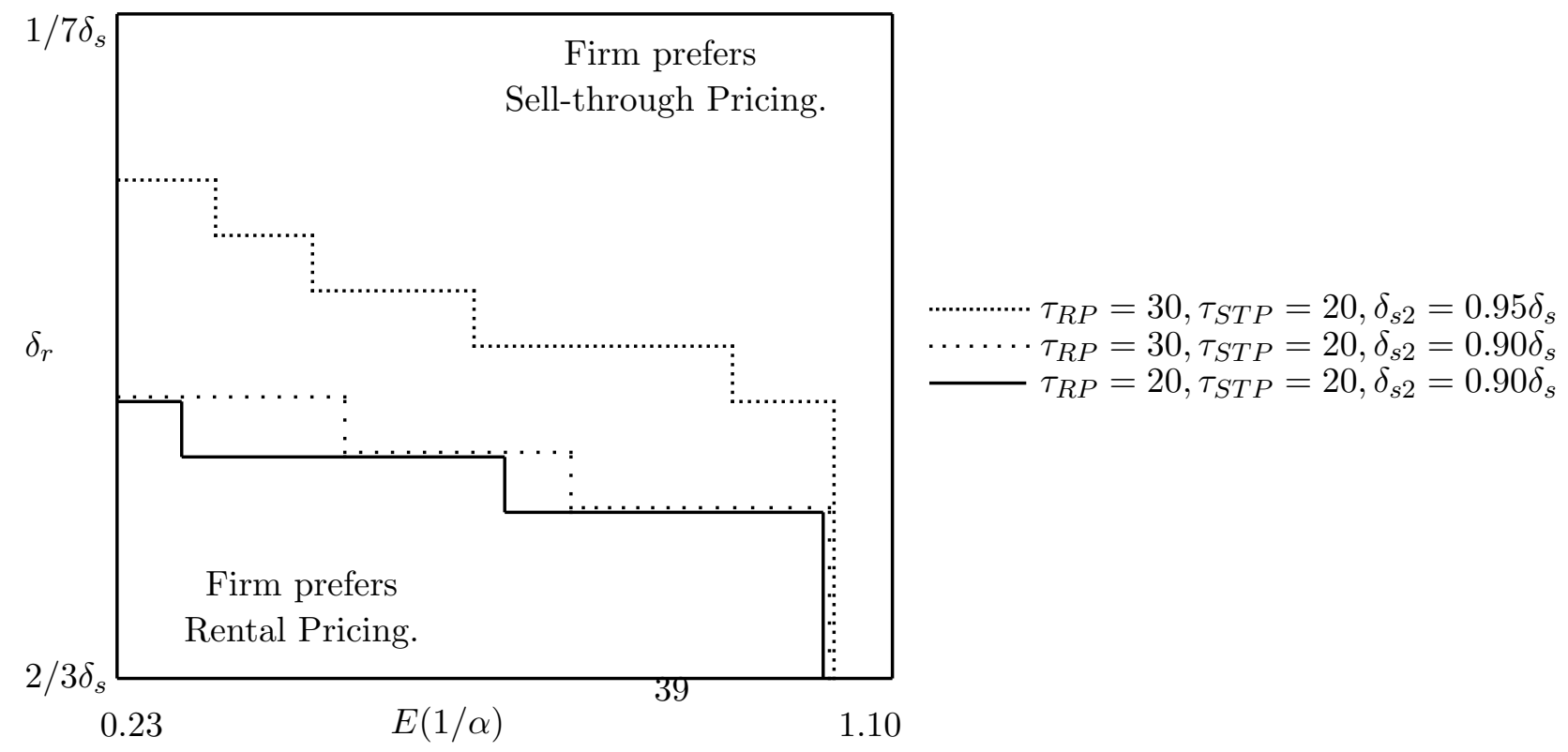




\section{Bibliography}

Bergstrom, T., (2001), "Free Labor for Costly Journals?," Journal of Economic Perspectives, Autumn.

Berry, S., (1994), "Estimating Discrete-Choice Models of Product Differentiation," RAND Journal of Economics, Vol. 25, pp. 242-62.

Bresnahan, T., (1987), "Competition and Collusion in the American Automobile Industry: The 1955 Price War," Journal of Industrial Economics, Vol. 35, No. 4, pp. 457-82.

Berry, S., Levinsohn, J., and A. Pakes, (1995), Automobile Prices in Market Equilibrium, Econometrica, Vol. 63, No. 4, pp. 841-90.

Borenstein, S., (1991), "Selling Costs and Switching Costs: Explaining Retail Gasoline Margins," RAND Journal of Economics, Vol. 22, pp. 354-69.

Borenstein, S. and N. Rose, (1994), "Competition and Price Dispersion in the U.S. Airline Industry," Journal of Political Economy, Vol. 102, pp. 653-83.

Busse, M. and M. Rysman, (2004), "Competition and Price Discrimination Yellow Pages Advertising," RAND Journal of Economics, forthcoming.

Cachon, G. and Lariviere, M., (2000), "Supply Chain Coordination with Revenue-Sharing Contracts: Strengths and Limitations," working paper.

Chevalier and Goolsbee, (2005), "Are Durable Goods Consumers Forward Looking? Evidence from College Textbooks," NBER working paper 11421.

Childs, R., (1992), "Home Video," in The Movie Business Book, Second edition, edited by Jason E. Squires, New York, NY: Simon and Schuster.

Clerides, S.K., (2002), "Book Value: Intertemporal Pricing and Quality Discrimination in the U.S. Market for Books," International Journal of Industrial Organization, Vol. 20, No. 10, pp. 1385-1408.

Dana, J. and Spier, K., (2001), "Revenue Sharing, Demand Uncertainty, and Vertical Control of Competing Firms," Journal of Industrial Economics, Vol. 49, No. 3, pp. $223-45$.

Deneckere, R. and P. McAfee, (1996), "Damaged Goods," Journal of Economics and Management Strategy, Vol. 5, No. 2, pp. 149-74.

Hansen, L., (1982), "Large Sample Properties of Generalized Method of Moments Estimators," Econometrica, Vol. 50, No. 4, pp. 1029-54.

Hausman, J., (1997), Valuation of New Goods under Perfect and Imperfect Competition, The Economics of New Goods. Bresnahan, Tim and Gordon, Robert, eds., NBER Research Studies in Income and Wealth, Vol 58, Chicago and London: University of Chicago Press, pp 209-37. 
Karaca-Mandic, P., (2003), Network Effects in Technology Adoption: The Case of DVD Players, working paper.

Eaton, J. and S. Kortum, (1996), "Trade in Ideas: Patenting and Productivity in the OECD," Journal of International Economics, Vol. 40, No. 2, pp. 251-78.

Leslie, P., (2004), "Price Discrimination in Broadway Theater," RAND Journal of Economics, V. 35, No. 3, pp. 520 - 41.

Liebowitz, S., (1985), "Copying and Indirect Appropriability: Photocopying of Journals," Journal of Political Economics, V. 93, No. 5, pp. 945 - 57.

McCalman, Phillip, (2001), "Reaping What You Sow: An Empirical Analysis of International Patent Harmonization," Journal of International Economics, Vol. 55, No. 1, pp. 161-86.

McCalman, Phillip, (2004), "Foreign Direct Investment and Intellectual Property Rights: Evidence from Hollywood's Global Distribution of Movies and Videos," Journal of International Economics, Vol. 62, No. 1, pp. 107-23.

Maskin, E. and Riley, J., (1984), "Monopoly with Incomplete Information," RAND Journal of Economics, Vol. 15, No. 2, pp. 171-96.

McManus, B., (2001), "Nonlinear Pricing in an Oligopoly Market: The Case of Specialty Coffee," working paper.

Miravete, E., (2002), "Estimating Demand for Local Telephone Service with Asymmetric Information and Optional Calling Plans," Review of Economic Studies Vol. 69, pp. 943-71.

Mortimer, J., (2001), An Empirical Study of Contractual Arrangements and Inventory: The U.S. Video Rental Industry, UCLA Dissertation.

Mortimer, J., (2004), Vertical Contracts in the Video Rental Industry, working paper.

Mussa, M. and Rosen, S., (1978), "Monopoly and Product Quality," Journal of Economic Theory, Vol. 18, No. 2, pp. 301-17.

Nevo, A., (2000), A Practitioner's Guide to Estimation of Random Coefficients Logit Models of Demand, Journal of Economics and Management Strategy, Vol. 9, No. 4, pp. 513-548.

Novos and Waldman, (1984), "The Effects of Increased Copyright Protection: An Analytic Approach," Journal of Political Economy, Vol. 92, pp. 236-46.

Ordover and Willig, (1978), "On the Optimal Provision of Journals qua Sometimes Shared Goods," American Economic Review, Vol. 68, No. , pp. 324-38.

Johnson, (1985), "The Economics of Copying," Journal of Political Economy, Vol. 93, pp. $158-74$. 
Takayama, (1994), "The Welfare Implications of Unauthorized Reproduction of Intellectual Property in the Presence of Demand Network Externalities," Journal of Industrial Economics, Vol. 42, pp. 155-66.

Takayama, (1997), "The Intertemporal Consequences of Unauthorized Reproduction of Intellectual Property," Journal of Law and Economics, Vol. 40, pp. 511-22.

Roehl, R. and Varian, H., (2001), Circulating Libraries and Video Rental Stores, First Monday, Vol. 6, No. 5.

Shepard, A., (1991), "Price Discrimination and Retail Configuration," Journal of Political Economy, Vol. 99, No. 1, pp. 30-53.

Song, M., (2004), Measuring Consumer Welfare in the CPU Market: An application of the pure characteristics demand model, working paper.

Tirole, J., (1995), The Theory of Industrial Organization, Cambridge, Massachusetts: The MIT Press.

Varian, H., (2000), "Buying, Sharing and Renting Information Goods," Journal of Industrial Economics, Vol 48, No. 4, pp 473-88.

Video Software Dealers Association, various Annual Reports.

www.bva.org.uk, British Video Association.

www.copyright.gov, Text of U.S. Copyright Act.

www.fipr.org/copyright/eucd.html, Text of Directive 2001/29/EC, European Union Copyright Directive, Section 6.

www.intellectual-property.gov.uk

Wyatt, E., (2005), "Google Library Database is Delayed," The New York Times, August 13, p. D1.

Yoon, K., (2002), "The Optimal Level of Copyright Protection," Information Economics and Policy, Vol 14, No. 3, pp 327-48. 
Table 1: Market Shares of Alternative Distribution Channels: Rentals and Sales*

\begin{tabular}{lrrrr} 
Retail Outlet & $\begin{array}{r}\text { VHS } \\
\text { Rental }\end{array}$ & $\begin{array}{r}\text { VHS } \\
\text { Sales }\end{array}$ & $\begin{array}{r}\text { DVD } \\
\text { Rental }\end{array}$ & $\begin{array}{r}\text { DVD } \\
\text { Sales }\end{array}$ \\
\hline \hline & $76.8 \%$ & $22.9 \%$ & $73.8 \%$ & $10.0 \%(1)$ \\
Video Specialty & 23.2 & 10.7 & 17.1 & $30.0(2)$ \\
$\begin{array}{l}\text { Other brick\&mortar/ } \\
\text { grocery stores, etc. }\end{array}$ & 0 & 1.9 & 9.1 & 10.0 \\
$\begin{array}{l}\text { Internet (Netflix, etc.) } \\
\begin{array}{l}\text { Discount merchandiser } \\
\text { (i.e., Walmart, etc) }\end{array}\end{array}$ & 0 & 55.1 & 0 & $40.0(3)$ \\
Other (direct mail, etc) & 0 & 9.4 & 0 & 10.0 \\
& & & & \\
\hline \hline
\end{tabular}

*Data Source: Alexander and Associates. Sales tabulations reflect activity for the second quarter of 2002; rental tabulations reflect activity for May 2002.

(1) Includes Blockbuster at 7 percent (mostly pre-viewed DVDs) and an allowance for other video specialty stores.

(2) Includes Best Buy at 20 percent, Circuit City at 5 percent, and an allowance for others at 5 percent.

(3) Includes Walmart at 29 percent, Target at 8 percent, and an allowance for others at 3 percent. 
Table 2: All A and B Titles Released on VHS, Jan 00 - Dec 01*

\begin{tabular}{lrrrr} 
& \multicolumn{2}{r}{ \% VHS ST priced } & \multicolumn{2}{r}{ Total Released } \\
Genre & A & B & A & B \\
\hline \hline & & & & \\
Act/Adv & 22.2 & 0.0 & 27 & 11 \\
Child/Fam & 100.0 & 100.0 & 13 & 4 \\
Comedy & 29.4 & 2.7 & 34 & 37 \\
Drama & 15.8 & 0.0 & 19 & 24 \\
Horror/Sus & 0.0 & 0.0 & 17 & 15 \\
Romance & 0.0 & 0.0 & 4 & 5 \\
Sci-Fi & 75.0 & 16.7 & 4 & 6 \\
& & & & \\
Total & 29.4 & 5.9 & 118 & 102 \\
& & & & \\
\hline \hline
\end{tabular}

Table 3: All A and B Titles Released on DVD, Jan 00 - Dec 01*

\begin{tabular}{lrrrr} 
& \multicolumn{2}{r}{ \% DV ST priced } & \multicolumn{2}{r}{ Total Released } \\
Genre & A & B & A & B \\
\hline \hline & & & & \\
Act/Adv & 100.0 & 100.0 & 27 & 11 \\
Child/Fam & 100.0 & 100.0 & 12 & 2 \\
Comedy & 100.0 & 100.0 & 27 & 37 \\
Drama & 100.0 & 96.0 & 19 & 25 \\
Horror/Sus & 100.0 & 100.0 & 13 & 16 \\
Romance & 100.0 & 100.0 & 4 & 5 \\
Sci-Fi & 100.0 & 100.0 & 4 & 7 \\
& & & & \\
Total & 100.0 & 99.0 & 106 & 103 \\
& & & & \\
\hline \hline
\end{tabular}

*Tabulations compiled by author using data from Rentrak Corporation. A titles grossed at least 40 million dollars in theatrical revenues. B titles grossed between 15 and 40 million dollars in theatrical revenues. Table includes all A and B titles released during the relevant time period, including those available on revenue-sharing terms. 
Table 4: Empirical Evidence on the Growth of DVD

\begin{tabular}{lrrr} 
(in millions) & 1999 & 2000 & 2001 \\
\hline \hline & & & \\
DVD Households (1) & & 12 & 24 \\
Total Expenditures: & & & \\
DVD Rentals (2) & 300 & 569 & 1,400 \\
DVD Sales (3) & 1,300 & 3,200 & 5,300 \\
Growth Rate over Previous Year & & \\
DVD Rentals (2) & $90 \%$ & $146 \%$ \\
DVD Sales (3) & $146 \%$ & $66 \%$ \\
Expenditures in my data & & \\
DVD Rentals (4) & 9.7 & 43.0 \\
DVD Sales (4) & 0.6 & 5.1 \\
& & \\
\hline \hline
\end{tabular}

(1) VSDA 2002 Annual Report, pg. 3. Source: Kagan World Media; www.adamsmediaresearch.com.

(2) VSDA 2002 Annual Report, pg. 3. Source: Vidtrac; www.adamsmediaresearch.com.

(3) VSDA 2002 Annual Report, pg. 13. Source: Adams Media Research.

(4) Author's calculations. (2000-2001 New Releases, Sample Stores Only) 
Table 5: Timing of Rentals and Sales: Cumulative Percentages by Month

\begin{tabular}{|c|c|c|c|c|c|c|}
\hline & \multicolumn{3}{|c|}{ VHS } & \multicolumn{3}{|c|}{ DVD } \\
\hline & Rentals & Used Sales & New Sales & Rentals & Used Sales & New Sales \\
\hline \multicolumn{7}{|c|}{ Panel 1: Rental Priced Titles $(\mathrm{N}=12)$ : } \\
\hline Month 1 & 39.9 & 0.3 & 3.0 & 44.7 & 7.7 & 23.4 \\
\hline Month 2 & 62.2 & 1.2 & 7.5 & 63.6 & 20.8 & 46.1 \\
\hline Month 3 & 77.2 & 14.7 & 11.0 & 75.1 & 37.9 & 66.7 \\
\hline Month 4 & 83.7 & 29.6 & 13.3 & 80.3 & 48.3 & 76.6 \\
\hline Month 5 & 88.1 & 44.4 & 14.7 & 84.8 & 56.7 & 83.2 \\
\hline Month 6 & 94.7 & 57.1 & 37.5 & 93.3 & 71.3 & 90.9 \\
\hline Month 7 & 100.0 & 69.6 & 74.4 & 100.0 & 84.2 & 94.5 \\
\hline Month 8 & 100.0 & 79.5 & 89.4 & 100.0 & 91.4 & 96.2 \\
\hline Months 9+ & 100.0 & 100.0 & 100.0 & 100.0 & 100.0 & 100.0 \\
\hline \multicolumn{7}{|c|}{ Panel 2: Sell-through Priced Titles $(\mathrm{N}=29)$ : } \\
\hline Month 1 & 44.1 & 1.8 & 50.1 & 44.4 & 5.9 & 17.4 \\
\hline Month 2 & 65.8 & 15.7 & 60.3 & 64.3 & 20.6 & 34.3 \\
\hline Month 3 & 76.9 & 38.5 & 65.2 & 77.7 & 42.2 & 61.3 \\
\hline Month 4 & 85.1 & 54.1 & 69.2 & 83.8 & 55.7 & 74.8 \\
\hline Month 5 & 88.1 & 65.8 & 71.4 & 88.2 & 67.6 & 84.2 \\
\hline Month 6 & 94.7 & 75.3 & 90.1 & 94.7 & 79.5 & 91.3 \\
\hline Month 7 & 100.0 & 84.6 & 95.7 & 100.0 & 87.3 & 94.1 \\
\hline Month 8 & 100.0 & 92.8 & 98.2 & 100.0 & 93.5 & 96.4 \\
\hline Months 9+ & 100.0 & 100.0 & 100.0 & 100.0 & 100.0 & 100.0 \\
\hline
\end{tabular}


Table 6: Monthly Average Prices of Rentals and Sales

\begin{tabular}{|c|c|c|c|c|c|c|}
\hline & \multicolumn{3}{|c|}{ VHS } & \multicolumn{3}{|c|}{ DVD } \\
\hline & Rentals & Used Sales & New Sales & Rentals & Used Sales & New Sales \\
\hline \multicolumn{7}{|c|}{ Panel 1: Rental Priced Titles $(\mathrm{N}=12)$ : } \\
\hline Month 1 & 3.00 & 11.84 & 97.74 & 3.04 & 8.45 & 16.87 \\
\hline Month 2 & 3.03 & 7.81 & 100.44 & 3.18 & 9.10 & 16.48 \\
\hline Month 3 & 3.01 & 7.92 & 97.65 & 3.29 & 8.33 & 16.53 \\
\hline Month 4 & 2.97 & 9.15 & 88.60 & 3.28 & 9.02 & 16.27 \\
\hline Month 5 & 3.03 & 8.44 & 96.40 & 3.23 & 9.28 & 15.60 \\
\hline Month 6 & 2.72 & 7.05 & 19.23 & 2.78 & 9.79 & 14.85 \\
\hline Month 7 & 2.72 & 6.29 & 18.80 & 2.78 & 9.93 & 14.90 \\
\hline Month 8 & 2.72 & 5.72 & 18.27 & 2.78 & 9.18 & 14.60 \\
\hline Months 9+ & 2.72 & 5.98 & 26.68 & 2.78 & 9.57 & 15.47 \\
\hline \multicolumn{7}{|c|}{ Panel 2: Sell-through Priced Titles $(\mathrm{N}=29)$ : } \\
\hline Month 1 & 3.01 & 7.79 & 17.48 & 3.05 & 10.40 & 19.50 \\
\hline Month 2 & 3.17 & 7.70 & 18.85 & 3.53 & 11.36 & 17.08 \\
\hline Month 3 & 3.18 & 7.36 & 20.30 & 3.67 & 11.27 & 15.67 \\
\hline Month 4 & 3.15 & 7.11 & 18.47 & 3.86 & 10.96 & 15.47 \\
\hline Month 5 & 3.12 & 7.00 & 18.34 & 3.80 & 10.87 & 14.60 \\
\hline Month 6 & 2.74 & 6.42 & 13.53 & 3.09 & 9.87 & 13.23 \\
\hline Month 7 & 2.74 & 6.41 & 14.34 & 3.09 & 9.87 & 14.01 \\
\hline Month 8 & 2.74 & 6.29 & 14.24 & 3.09 & 9.46 & 12.54 \\
\hline Months $9+$ & 2.74 & 6.00 & 15.19 & 3.09 & 9.87 & 11.61 \\
\hline
\end{tabular}


Table 7: Weighted Quantities of Rentals and Sales

\begin{tabular}{|c|c|c|c|c|c|c|}
\hline & \multicolumn{3}{|c|}{ VHS } & \multicolumn{3}{|c|}{ DVD } \\
\hline & Rentals & Used Sales & New Sales & Rentals & Used Sales & New Sales \\
\hline $\begin{array}{l}\text { Panel 1: Rental I } \\
\text { Total per }\end{array}$ & riced Tit & $\mathrm{s}(\mathrm{N}=12)$ & & & & \\
\hline Title ('000) & 1112.2 & 20.3 & 0.2 & 129.6 & 3.7 & 1.5 \\
\hline $\begin{array}{l}\text { Weighted Total } \\
\text { per Title }\end{array}$ & 4054.9 & 56.8 & 248.5 & 491.7 & 10.4 & 136.6 \\
\hline $\begin{array}{l}\text { Ratio, Weighted } \\
\text { Sales/Rentals }\end{array}$ & & & $7.5 \%$ & & & $29.9 \%$ \\
\hline $\begin{array}{l}\text { Panel 2: Sell-thrc } \\
\text { Total per }\end{array}$ & ugh Price & Titles $(\mathrm{N}=$ & 29): & & & \\
\hline Title ('000) & 910.5 & 39.2 & 0.5 & 131.8 & 5.0 & 0.9 \\
\hline $\begin{array}{l}\text { Weighted Total } \\
\text { per Title } \\
\text { Ratio, Weighted }\end{array}$ & 3319.5 & 109.8 & 327.3 & 500.1 & 14.0 & 158.4 \\
\hline Sales/Rentals & & & $13.2 \%$ & & & $34.5 \%$ \\
\hline
\end{tabular}


Table 8: Estimated Parameter Values

VHS

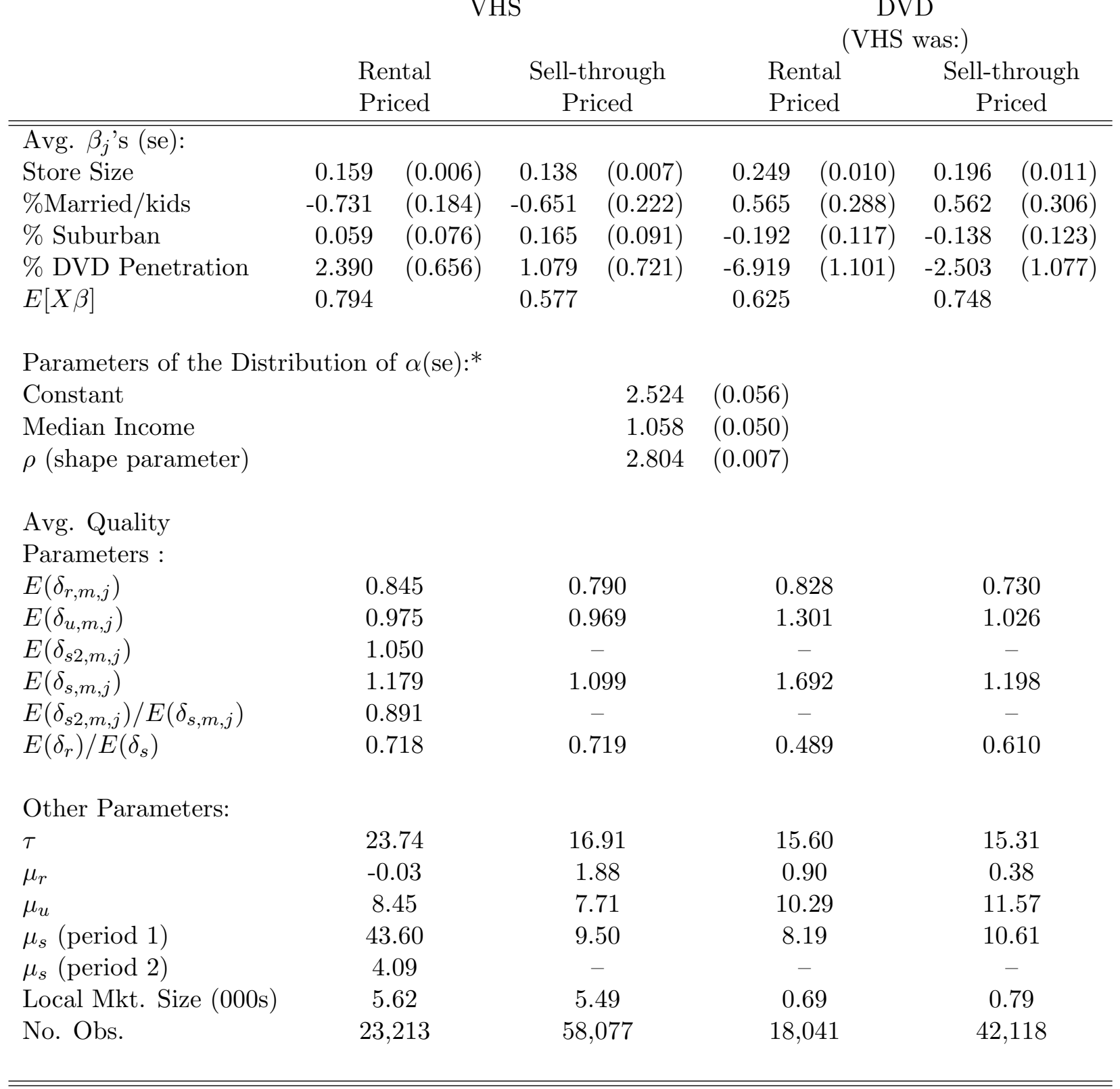

${ }^{*}$ Constant across titles. 
Table 9: Counterfactual Exercises, VHS

Actual Current "Other" Mkt. Seg.

\begin{tabular}{|c|c|c|c|c|}
\hline \multicolumn{5}{|l|}{ Rental Priced Titles (12): } \\
\hline$p_{w}^{r}$ & 52.43 & 57.59 & 31.58 & 38.49 \\
\hline$p_{s}($ per 1$)$ & 109.13 & 104.58 & 41.35 & 35.99 \\
\hline$p_{s}($ per 2$)$ & 20.46 & 16.98 & - & - \\
\hline$p_{u}$ & 8.45 & 8.63 & 8.48 & 8.62 \\
\hline$p_{r}$ & 2.92 & 2.83 & 3.36 & 2.49 \\
\hline$\%$ New (per 1 ) & 0.16 & 0.24 & 0.11 & 0.35 \\
\hline$\%$ New (per 2) & 0.34 & 0.98 & - & - \\
\hline$\%$ Used & 0.40 & 0.32 & 0.52 & 0.34 \\
\hline$\%$ Rent & 29.35 & 32.12 & 25.29 & 38.43 \\
\hline Avg. $\pi_{\text {stud }}$ (Mil.) & 5.77 & 5.68 & 4.85 & 4.14 \\
\hline Avg. $\pi_{r e t}$ (Mil.) & 3.01 & 3.12 & 3.42 & 2.43 \\
\hline$\%$ Change $\pi_{\text {stud }}$ & - & -1.53 & -14.57 & -27.06 \\
\hline$\%$ Change $\pi_{r e t}$ & - & 3.63 & 9.68 & -21.99 \\
\hline \% Change Con. Surplus & - & - & -22.23 & -15.46 \\
\hline \multicolumn{5}{|c|}{ Sell-through Priced Titles (29): } \\
\hline$p_{w}^{r}$ & 14.49 & 16.07 & 32.41 & 47.99 \\
\hline$p_{s}($ per 1$)$ & 24.00 & 25.67 & 76.13 & 21.44 \\
\hline$p_{s}($ per 2$)$ & - & - & 19.54 & - \\
\hline$p_{u}$ & 7.71 & 7.71 & 7.80 & 7.79 \\
\hline$p_{r}$ & 2.94 & 3.04 & 1.70 & 2.57 \\
\hline$\%$ New (per 1 ) & 0.86 & 1.44 & 0.07 & 2.22 \\
\hline$\%$ New (per 2) & - & - & 1.17 & - \\
\hline$\%$ Used & 0.81 & 0.47 & 0.35 & 0.14 \\
\hline$\%$ Rent & 25.43 & 24.09 & 46.67 & 27.97 \\
\hline Avg. $\pi_{s t u d}($ Mil.) & 3.53 & 4.68 & 3.29 & 4.93 \\
\hline Avg. $\pi_{r e t}$ (Mil.) & 6.41 & 6.31 & 2.02 & 2.29 \\
\hline$\%$ Change $\pi_{\text {stud }}$ & - & 32.73 & -29.81 & 5.32 \\
\hline$\%$ Change $\pi_{r e t}$ & - & -1.46 & -68.01 & -63.77 \\
\hline \% Change Con. Surplus & - & - & -9.49 & -30.89 \\
\hline
\end{tabular}

*Retail and studio profits are weighted to include all outlets.

'Current' uses actual $\mu$ and $\tau$.

'Other' uses counterfactual $\mu$ and $\tau$.

'Mkt. Segm.' uses $\mu_{r}$ and $\tau$ from rental pricing; $\mu_{s}$ from sell-through. 
Table 10: Counterfactual Exercises, DVD

Actual Current "Other" Mkt. Seg.

\begin{tabular}{|c|c|c|c|c|}
\hline \multicolumn{5}{|c|}{ VHS was Rental Priced (12): } \\
\hline$p_{w}^{r}$ & 15.55 & 15.10 & 31.84 & 35.92 \\
\hline$p_{s}($ per 1$)$ & 23.75 & 23.99 & 75.40 & 21.62 \\
\hline$p_{s}($ per 2$)$ & - & - & 21.43 & - \\
\hline$p_{u}$ & 10.29 & 10.28 & 10.31 & 10.28 \\
\hline$p_{r}$ & 2.81 & 2.81 & 1.52 & 1.90 \\
\hline$\%$ New (per 1 ) & 5.66 & 7.52 & 0.29 & 10.42 \\
\hline$\%$ New (per 2) & - & - & 2.97 & - \\
\hline$\%$ Used & 0.28 & 0.05 & 0.65 & -0.02 \\
\hline$\%$ Rent & 24.47 & 26.63 & 55.01 & 37.69 \\
\hline Avg. $\pi_{\text {stud }}$ (Mil.) & 0.96 & 1.15 & 0.72 & 1.21 \\
\hline Avg. $\pi_{r e t}$ (Mil.) & 0.58 & 0.63 & 0.34 & 0.34 \\
\hline$\%$ Change $\pi_{\text {stud }}$ & - & 20.14 & -37.48 & 4.74 \\
\hline$\%$ Change $\pi_{r e t}$ & - & 7.49 & -45.03 & -46.22 \\
\hline$\%$ Change Con. Surplus & - & - & -8.51 & 36.10 \\
\hline \multicolumn{5}{|c|}{ VHS was Sell-through Priced (29): } \\
\hline$p_{w}^{r}$ & 17.16 & 17.42 & 33.18 & 39.93 \\
\hline$p_{s}($ per 1$)$ & 27.77 & 28.44 & 76.58 & 23.59 \\
\hline$p_{s}($ per 2$)$ & - & - & 21.75 & - \\
\hline$p_{u}$ & 11.57 & 11.38 & 11.39 & 11.41 \\
\hline$p_{r}$ & 2.81 & 2.92 & 1.63 & 2.19 \\
\hline$\%$ New (per 1 ) & 2.62 & 3.96 & 0.09 & 5.85 \\
\hline$\%$ New (per 2) & - & - & 2.91 & - \\
\hline$\%$ Used & 0.34 & 0.24 & 0.37 & 0.05 \\
\hline$\%$ Rent & 22.80 & 25.95 & 48.14 & 33.43 \\
\hline Avg. $\pi_{\text {stud }}$ (Mil.) & 0.72 & 0.84 & 0.55 & 0.90 \\
\hline Avg. $\pi_{r e t}$ (Mil.) & 0.61 & 0.61 & 0.28 & 0.25 \\
\hline$\%$ Change $\pi_{\text {stud }}$ & - & 16.80 & -34.91 & 6.50 \\
\hline$\%$ Change $\pi_{r e t}$ & - & 0.57 & -54.31 & -59.99 \\
\hline \% Change Con. Surplus & - & - & -5.14 & 12.97 \\
\hline
\end{tabular}

*Retail and studio profits are weighted to include all outlets.

'Current' uses actual $\mu$ and $\tau$.

'Other' uses counterfactual $\mu$ and $\tau$.

'Mkt. Segm.' uses $\mu_{r}$ and $\tau$ from rental pricing; $\mu_{s}$ from sell-through. 
Table 11: Counterfactual Exercises, Future DVD

Sell-thru Rental Mkt.

Priced Priced Segm.

\begin{tabular}{|c|c|c|c|}
\hline \multicolumn{4}{|c|}{ "VHS was Rental Priced (12): } \\
\hline$p_{w}^{r}$ & 25.90 & 52.11 & 39.93 \\
\hline$p_{s}($ per 1$)$ & 35.89 & 96.53 & 25.11 \\
\hline$p_{s}($ per 2$)$ & - & 16.79 & - \\
\hline$p_{u}$ & 8.57 & 8.65 & 8.64 \\
\hline$p_{r}$ & 2.94 & 2.56 & 2.47 \\
\hline$\%$ New (per 1) & 0.22 & 0.22 & 1.52 \\
\hline$\%$ New (per 2) & - & 2.26 & - \\
\hline$\%$ Used & 1.86 & 1.07 & 1.32 \\
\hline$\%$ Rent & 35.35 & 41.27 & 43.38 \\
\hline Avg. $\pi_{\text {stud }}$ (Mil.) & 5.48 & 6.80 & 5.66 \\
\hline Avg. $\pi_{r e t}$ (Mil.) & 5.07 & 4.07 & 3.64 \\
\hline$\%$ Change $\pi_{\text {stud }}$ & - & 24.09 & 3.33 \\
\hline$\%$ Change $\pi_{r e t}$ & - & -19.67 & -28.28 \\
\hline$\%$ Change Con. Surplus & - & 18.02 & 5.00 \\
\hline \multicolumn{4}{|c|}{ VHS was Sell-through Priced (29): } \\
\hline$p_{w}^{r}$ & 15.06 & 29.55 & 35.56 \\
\hline$p_{s}($ per 1$)$ & 24.88 & 73.58 & 23.96 \\
\hline$p_{s}($ per 2$)$ & - & 19.12 & - \\
\hline$p_{u}$ & 7.75 & 7.73 & 7.71 \\
\hline$p_{r}$ & 3.00 & 1.53 & 2.00 \\
\hline$\%$ New (per 1) & 1.45 & 0.07 & 2.19 \\
\hline$\%$ New (per 2) & - & 1.59 & - \\
\hline$\%$ Used & 0.70 & 0.77 & 0.58 \\
\hline$\%$ Rent & 19.91 & 38.83 & 28.31 \\
\hline Avg. $\pi_{s t u d}($ Mil.) & 2.87 & 2.73 & 3.80 \\
\hline Avg. $\pi_{r e t}$ (Mil.) & 3.97 & 1.59 & 1.87 \\
\hline$\%$ Change $\pi_{s t u d}$ & - & -4.80 & 32.54 \\
\hline$\%$ Change $\pi_{r e t}$ & - & -59.91 & -52.86 \\
\hline \% Change Con. Surplus & - & 12.54 & 1.94 \\
\hline
\end{tabular}

* Retail and studio profits are weighted to include all outlets.

'Current' uses actual $\mu$ and $\tau$.

'Other' uses counterfactual $\mu$ and $\tau$.

'Mkt. Segm.' uses $\mu_{r}$ and $\tau$ from rental pricing; $\mu_{s}$ from sell-through. 